\title{
What Kinds of Atmospheric Anomalies Drive Wintertime North Pacific Basin-Scale Subtropical Oceanic Front Intensity Variation?
}

\author{
RAN ZHANG, JiABEI FANG, AND XIU-QUN YANG \\ China Meteorological Administration-Nanjing University Joint Laboratory for Climate Prediction Studies, School of \\ Atmospheric Sciences, Nanjing University, Nanjing, China
}

(Manuscript received 22 December 2019, in final form 18 April 2020)

\begin{abstract}
The basin-scale subtropical oceanic front zone (STFZ) is a key region for midlatitude air-sea interaction in the North Pacific. However, previous studies considered midlatitude sea surface temperature (SST) variabilities as a response to atmospheric stochastic forcing. With reanalysis and observational data, this study investigates what kinds of atmospheric anomalies drive the wintertime North Pacific STFZ intensity variation. Lead correlations show that prior to the STFZ's enhancement, there exist persistent atmospheric anomalies characterized by a negative-phase Arctic Oscillation (AO) and a positive-phase Pacific-North American (PNA) pattern, lasting for up to 80 and 50 days and peaking at 20- and 8-day leads, respectively. It is further found that the long-lasting negative-phase AO is conducive to stronger low-tropospheric baroclinicity at around $40^{\circ} \mathrm{N}$ over North Pacific where there is a climatological baroclinic region. The stronger baroclinicity leads to more synoptic transient eddy activities, promoting an equivalent barotropic low geopotential height anomaly north of STFZ via transient eddy vorticity forcing. The geopotential height anomaly propagates downstream, triggering a PNA-like pattern. With such an AO-promoted atmospheric internal wave-flow feedback, the regional PNA pattern is intensified and embedded in the annular AO mode, accompanied with an intensified Aleutian low and surface westerly wind that peak at an 8-day lead, preconditioning a persistent (nonstochastic) atmospheric forcing on the STFZ. The intensified surface westerly predominantly tends to drive a southward Ekman transport and increase upward surface turbulent heat fluxes into the atmosphere through increasing surface wind speed and sea-air temperature difference, amplifying the underlying negative SST anomaly and cross-frontal meridional SST gradient, ultimately intensifying the STFZ.
\end{abstract}

\section{Introduction}

Observational studies indicate the existence of the oceanic frontal zone in the midlatitude North Pacific basin, characterized by a significant sea surface temperature (SST) gradient. Oceanic frontal zones are proved to be key regions for air-sea interaction in the midlatitudes (Stommel 1958; Feliks et al. 2004, 2007; Minobe et al. 2008; Taguchi et al. 2009; Sampe et al. 2010). On the one hand, SST is an indispensable variable for the midlatitude air-sea interaction system and large midlatitude SST variations are primarily located in oceanic frontal zones (Nakamura and Kazmin 2003;

¿ Denotes content that is immediately available upon publication as open access.

Corresponding authors: Xiu-Qun Yang, xqyang@nju.edu.cn; Jiabei Fang, fangjb@nju.edu.cn
Fang and Yang 2016; Yao et al. 2017, 2018; Tao et al. 2019). On the other, strong atmospheric baroclinicity is found to be associated with oceanic fronts especially in boreal winter. According to the oceanic baroclinic adjustment mechanism, the oceanic front supplies more (less) sensible heat flux on its warm flank (cold flank), which recovers the poleward eddy-induced heat flux transport, and thus sustains the cross-frontal air temperature gradient and baroclinicity in the lower troposphere (Nakamura et al. 2008; Sampe et al. 2010). Powerful baroclinicity benefits vigorous synoptic-scale transient eddy (TE) activities and also connects closely with storm tracks and westerly jets in the Northern Hemisphere, which seem to be anchored by oceanic fronts (Nakamura and Shimpo 2004; Di Lorenzo et al. 2008; Ren et al. 2010; Chu et al. 2013; Yao et al. 2016). Besides, numerical studies show that if the midlatitude oceanic frontal zones are smoothed, then the TE activities, storm tracks, and westerly jets would be notably weakened. This implies the crucial role of oceanic fronts in the 
midlatitude air-sea interaction from the opposite angle of view (Minobe et al. 2008; Nakamura et al. 2008; Taguchi et al. 2009; Sampe et al. 2010).

There are two remarkable basin-scale oceanic frontal zones in the midlatitude North Pacific, called the subtropical frontal zone (STFZ) and subarctic frontal zone (SAFZ), both featuring considerable meridional SST gradients especially in winter (Nakamura et al. 2004). Wang et al. (2017) captured the basin-scale characteristics of wintertime SST anomalies in the North Pacific and defined new indexes to quantify the intensity and location variations of the two oceanic fronts. They found that the STFZ-related and SAFZ-related SST anomalies respectively resemble the Pacific decadal oscillation (PDO) pattern and the North Pacific Gyre Oscillation (NPGO) pattern, which are respectively defined as the leading and second empirical orthogonal function (EOF) mode of SST variability in the North Pacific (Mantua et al. 1997; Di Lorenzo et al. 2008). The PDO appears to be a major decadal-to-interdecadal signature in both ocean and atmosphere, implying the existence of midlatitude air-sea interaction (Minobe 1997; Zhu and Yang 2003; Schneider and Cornuelle 2005; Newman et al. 2016). Therefore, it is important to make it clear how the PDO-related SST anomaly is related to the STFZ. Besides, midlatitude North Pacific air-sea interaction occurs on an interdecadal time scale represented by the PDO, which can be explained by a variety of delayed negative feedback mechanisms associated with the role of propagation of oceanic Rossby wave (Frankignoul et al. 1997; Jin 1997; Huck and Vallis 2001; Qiu 2003; Qiu et al. 2007), the oceanic gyre circulation adjustment (Cessi 2000; Latif and Barnett 1994), and the oceanic subduction processes (Schneider et al. 1999). However, there is still a lack of possible positive air-sea feedback that can be assumed to stimulate, amplify, and sustain air-sea interaction on a relatively short time scale. In such a positive feedback, the forcing from the atmosphere is more significant than the reverse. Since the STFZ has been proposed to be one of the key ingredients in a hypothesized positive air-sea feedback loop in the midlatitude North Pacific (Fang and Yang 2016; Wang et al. 2017), it is of interest to investigate the atmospheric forcing on the STFZ as well as the mechanism responsible for the intensity variation of the STFZ.

It is well known that there exist strong internal chaotic variabilities in the midlatitude atmosphere, and the forcing from these atmospheric variabilities on the ocean is usually believed to be stochastic. Early studies proposed that the atmosphere-to-ocean stochastic forcing can lead to low-frequency oceanic variabilities in the midlatitudes. The ocean, with high heat capacity, can store the memory of the high-frequency variabilities from the atmosphere, and finally lead to oceanic low- frequency variations. It was found that a decadal time scale red-noise temperature response can be generated in the mixed layer of midlatitude ocean as a consequence of the atmospheric white-noise forcing within a simple theoretical model (Hasselmann 1976). Stochastic forcing from sea surface wind can lead to an interdecadal signal in midlatitude SST fields, with additional consideration of oceanic advection transportation (Saravanan and McWilliams 1998) or transportation of midlatitude oceanic Rossby waves (Frankignoul et al. 1997) in simple ocean models. Stochastic forcing from surface heat flux can also induce an interdecadal signal in the midlatitude upper ocean temperature field in the air-sea coupling model (Power et al. 1995; Delworth and Greatbatch 2000). However, over the key oceanic regions like the STFZ, whether or not the atmospheric forcing on the ocean is stochastic remains uncertain.

This study aims at investigating the atmospheric forcing determining the intensity variation of the basin-scale STFZ in wintertime North Pacific. The emphasis is put on the STFZ-related atmospheric anomalies and their internal connections. The concrete dynamical and thermal processes associated with the STFZ intensity variation forced by the atmospheric anomalies are also discussed. The paper is organized as follows. The data used are introduced in section 2. Typical atmospheric forcing on the STFZ and the relationships among corresponding atmospheric modes are analyzed and presented in section 3. Mechanisms responsible for how the atmospheric anomalies can affect the STFZ are investigated in section 4 . The final section is devoted to conclusions and discussion.

\section{Data}

The high-resolution SST data are obtained from the Optimum Interpolation SST version 2 data (OISST) and used to analyze the intensity variations of oceanic fronts in this study. It is downloaded from the National Oceanic and Atmospheric Administration (NOAA), with spatial resolution of $0.25^{\circ}$ and temporal resolution of 1 day (Banzon et al. 2016). Daily mean atmospheric variables at multiple levels (up to 12 levels) are applied, including geopotential height, air temperature, and 3D wind speed, obtained from the National Centers for Environmental Prediction-National Center for Atmospheric Research (NCEP-NCAR), at $2.5^{\circ}$ spatial resolution (Kalnay et al. 1996). Daily $1^{\circ} \times 1^{\circ}$ products from the Objectively Analyzed Air-Sea Heat Flux (OAFlux) (Yu and Weller 2007; Yu et al. 2008) are used, including air-sea interface latent heat (LH) flux, sensible heat (SH) flux, 10-m surface wind speed $\left(W_{s}\right), 2$-m surface air temperature $\left(T_{a}\right)$, sea surface temperature $\left(T_{s}\right)$, and 2-m surface air specific humidity 
(a) SST \& SST gradient

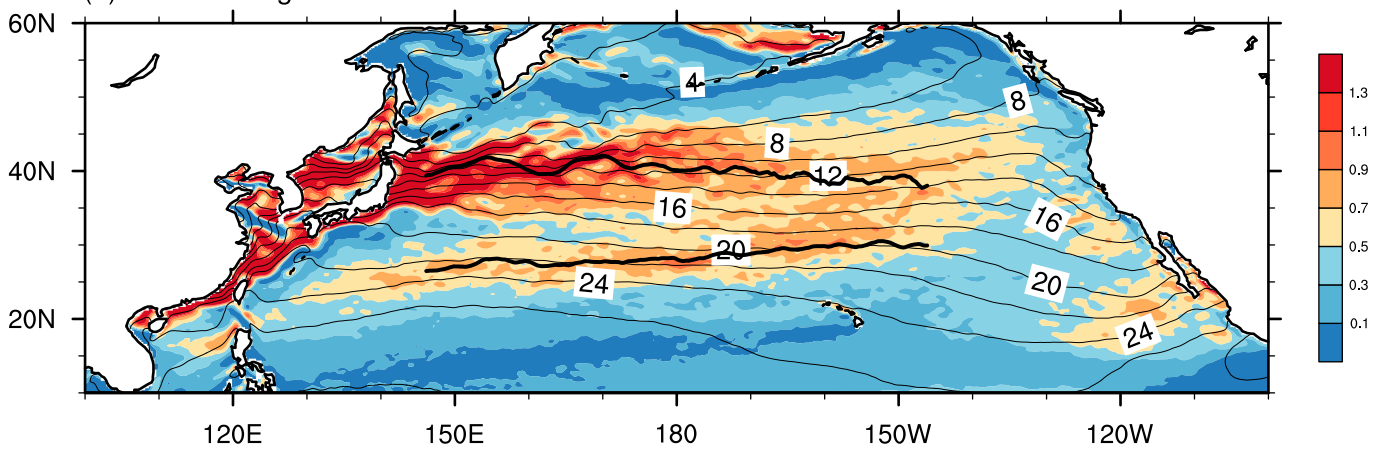

(b) Regressed SST on ITS_STFZ

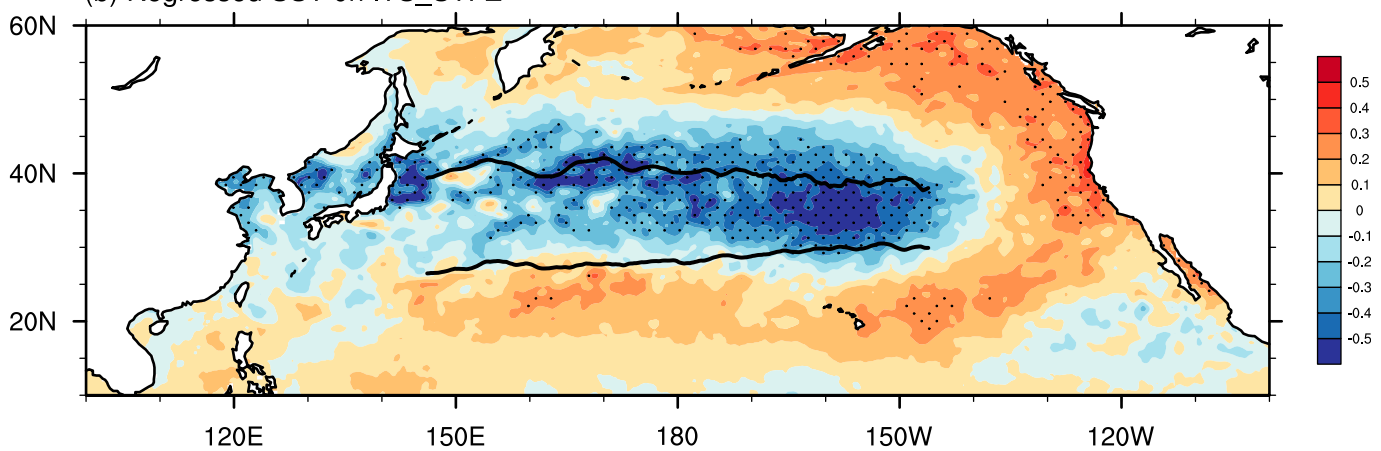

(c) Regressed SST on ITS_SAFZ

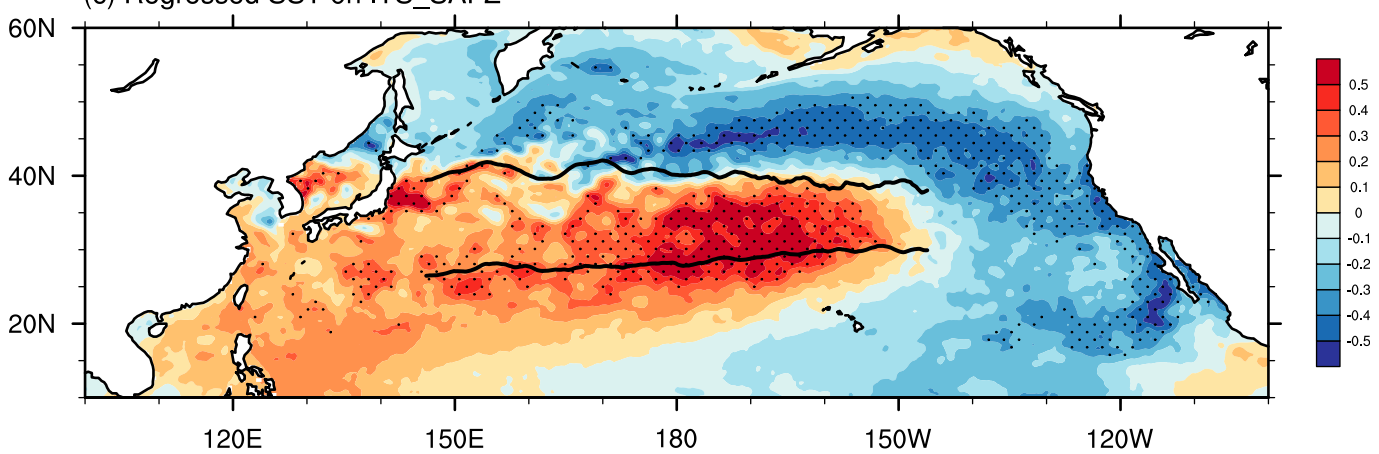

FIG. 1. Horizontal distributions of wintertime climatological (a) SST $\left({ }^{\circ} \mathrm{C}\right.$; contoured) and meridional SST gradient (- $\mathrm{SSST} / \partial y ; 10^{-5} \mathrm{~K} \mathrm{~m}^{-1}$; shaded), and regressed SST anomalies (K; shaded) upon wintertime standardized intensity indexes of (b) STFZ (ITS_STFZ) and (c) SAFZ (ITS_SAFZ). The thick black lines indicate the climatological locations of the STFZ and SAFZ, respectively. The black stippling denotes the regions passing the bootstrapping test at the $95 \%$ significance level.

$\left(Q_{a}\right)$. Besides, downward net heat flux $\left(Q_{\text {net }}\right)$ data are also taken from the OAFlux dataset, which is calculated as the sum of downward shortwave radiative flux, upward longwave radiative flux, upward latent heat flux, and upward sensible heat flux. Daily atmospheric indexes including AO, PNA, and NAO are all directly downloaded from the Climate Prediction Center/National Ocean Atmosphere Administration (CPC/NOAA). Other ocean elements, such as upper-layer oceanic temperature and 3D oceanic current components, are obtained from the Simple Ocean Data Assimilation (SODA) version 2.2.4 monthly data on $1^{\circ} \times 1^{\circ}$ grid (Carton et al. 2000). For the unification of different datasets, the time span in this study is all set to be 1985-2010. The wintertime is defined as December, January, and February (DJF). All variables are preprocessed by removing their climatological annual cycle.

\section{Persistent atmospheric forcing on the STFZ}

a. Persistent atmospheric modes associated with the STFZ's intensity variation

Climatologically, the isotherms of wintertime North Pacific SST are zonally distributed but are intensive in the Kuroshio Extension and subtropical countercurrent areas 

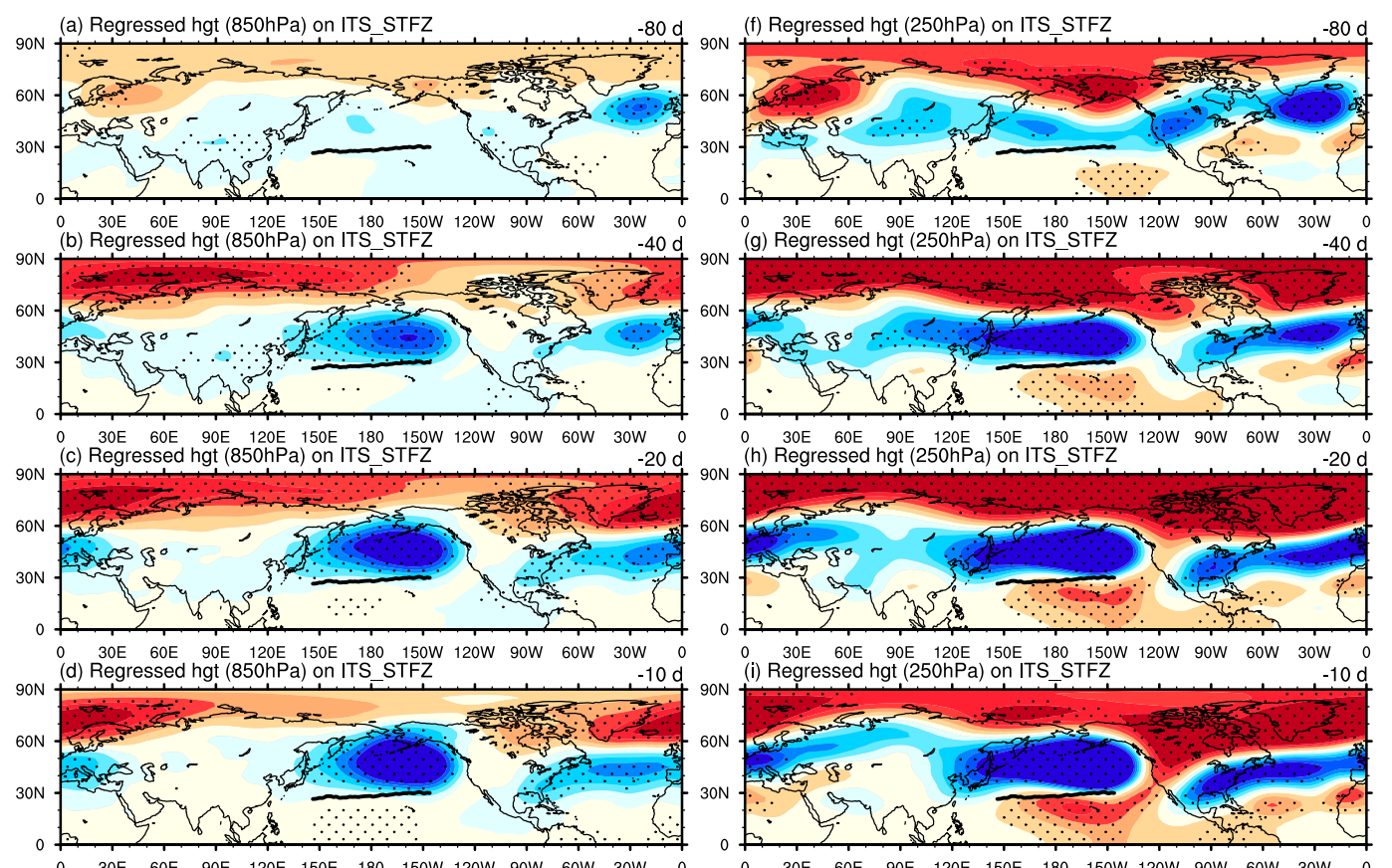

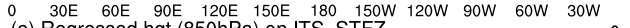
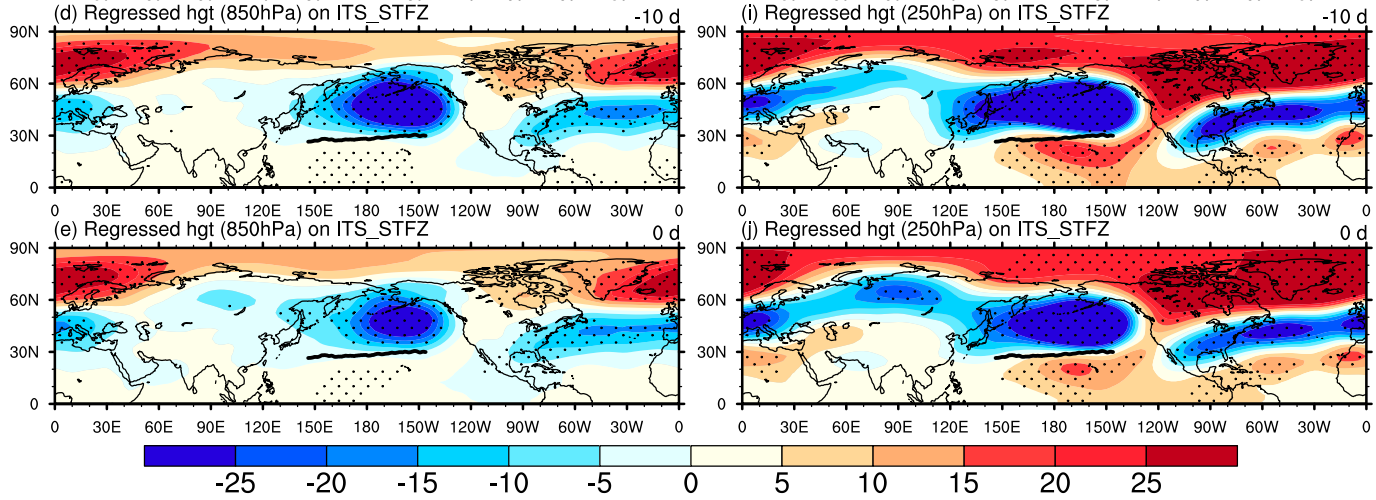

(j) Regressed hgt $(250 \mathrm{hPa})$ on ITS_STFZ

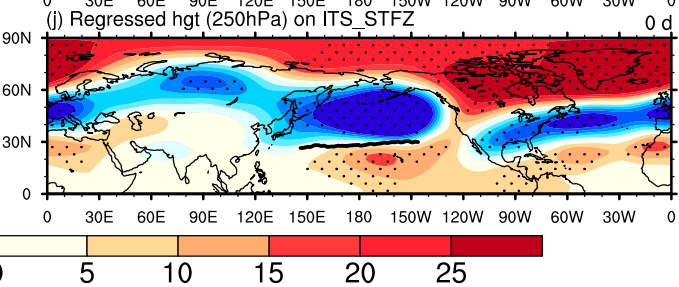

FIG. 2. Time-lead regressions of (left) 850- and (right) 250-hPa geopotential height anomalies (m; shaded) upon wintertime standardized intensity index of STFZ (ITS_STFZ) on (a),(f) day -80,(b),(g) day -40, (c),(h) day -20, (d),(i) day -10 , and (e),(j) day 0 . The negative time leads denote that the geopotential height anomaly leads ITS_STFZ and day 0 denotes simultaneous regression. The thick black lines indicate climatological location of STFZ. The black stippling denotes the regions passing the bootstrapping test at the $95 \%$ significance level.

(Fig. 1a). By computing SST meridional gradient, the feature of latitudinal SST variation is clearly captured. There are two obvious large value areas of basin-scale meridional SST gradient around $30^{\circ}$ and $40^{\circ} \mathrm{N}$, corresponding to the so-called subtropical frontal zone (STFZ) and subarctic frontal zone (SAFZ), respectively, as shown in Fig. 1a. Following the definition of Wang et al. (2017), the intensity indexes of STFZ and SAFZ (abbreviated as ITS STFZ and ITS_SAFZ, respectively) are computed as

$$
\mathrm{ITS}=\sum_{i=1}^{N} G_{i} / N
$$

where $G_{i}$ is the meridional SST gradient zonally averaged over $145^{\circ} \mathrm{E}-145^{\circ} \mathrm{W}$ that exceeds a given critical value $\left(0.45 \times 10^{-5} \mathrm{~K} \mathrm{~m}^{-1}\right.$ for STFZ, and $0.8 \times 10^{-5} \mathrm{~K} \mathrm{~m}^{-1}$ for SAFZ) at the $i$ th latitudinal grid point within the front zone, and $N$ is the total number of the grid points that satisfy the criteria. The wintertime SST anomalies are simultaneously regressed upon these indexes, as shown in Figs. 1b and 1c. As indicated in Wang et al. (2017), the ITS_STFZ and ITS_SAFZ regressed SST anomaly patterns indeed exhibit the features of positive-phase PDO and NPGO patterns, respectively. Considering that the PDO is the primary decadal variability in the midlatitude North Pacific (Liu 2012; Mantua et al. 1997; Minobe 1997; Newman et al. 2016; Zhu and Yang 2003), the following analyses will focus on the intensity variation of the PDO-related STFZ as well as the associated atmospheric modes.

Through time-lead regressing geopotential height anomalies upon wintertime ITS_STFZ, atmospheric anomaly patterns that lead the STFZ's intensity variation by up to 80 days are illustrated in Fig. 2. From the low- to high-level atmosphere, geopotential height anomalies exhibit an equivalent barotropic structure in the vertical direction. Prior to the wintertime STFZ's enhancement, a dipole pattern with a positive (negative) annular anomaly over the 
Arctic region (midlatitudes) appears early at an 80-day lead (Figs. 2a,f), featuring a negative-phase Arctic Oscillation (AO) pattern (Thompson and Wallace 1998). With time evolution (lead time from day -80 to day 0 ), the regional negative (positive) geopotential height anomaly centers over both North Pacific and southeast North America (northwest North America and around Hawaii) become clear, resembling a positive-phase Pacific-North American (PNA) pattern. Meanwhile, a negative-phase North Atlantic Oscillation (NAO) anomaly pattern gradually arises, with a positive (negative) anomaly center over Iceland (the Azores) (Figs. 2b,g) (Horel and Wallace 1981; Wallace and Gutzler 1981; Hurrell et al. 2003). The negative-phase AO and NAO anomalies and positivephase PNA anomaly appear to be extraordinarily strong when the atmospheric anomalies lead the STFZ's enhancement by around 20 days (Figs. 2c,h) and 10 days (Figs. 2d,i). Until day 0 (no lead), there is still coexistence of global zonally symmetric AO anomaly and regional PNA and NAO anomalies (Figs. 2e,j), although the signals are relatively weak when compared with those at 10-20-day leads. These lead regressions give a hint that persistent atmospheric AO, PNA, and NAO anomalies seem to be associated with the wintertime STFZ intensity variation. Since the STFZ intensity variation is PDO-related, for a consistency check we also calculated the regression pattern of geopotential height anomaly upon the PDO index (not shown), which greatly resembles Fig. 2. To some extent, it implies the possibility of long-lasting atmospheric forcing on the PDO-related SST in the STFZ.

To further investigate possible roles of those atmospheric modes in driving wintertime STFZ intensity variation, Fig. 3 presents the lead-lag cross-correlations between any of the three atmospheric mode (AO, PNA, and NAO) daily indexes and the wintertime STFZ intensity daily index (ITS_STFZ). Prior to the enhancement of STFZ, significant correlation between AO and ITS_STFZ starts early at an about 80-day lead and peaks with a coefficient value of -0.471 at a 20 -day lead. Combined with Fig. 2, it suggests again that the negativephase AO has a leading positive correlation with the STFZ's intensity. Meanwhile, a significant leading positive correlation of PNA with ITS_STFZ lasts for up to 50 days and the coefficient hits its maximum value of 0.469 at an 8-day lead, indicating an impact of positivephase PNA anomaly on the STFZ's enhancement. Similar to the AO, the negative-phase NAO also has a significant leading positive correlation with ITS_STFZ, which sustains 40 days or so and becomes the largest at a 20-day lead. The above results reveal that when the atmosphere leads the wintertime STFZ intensity variation, the AO, PNA, and NAO anomalies successively emerge

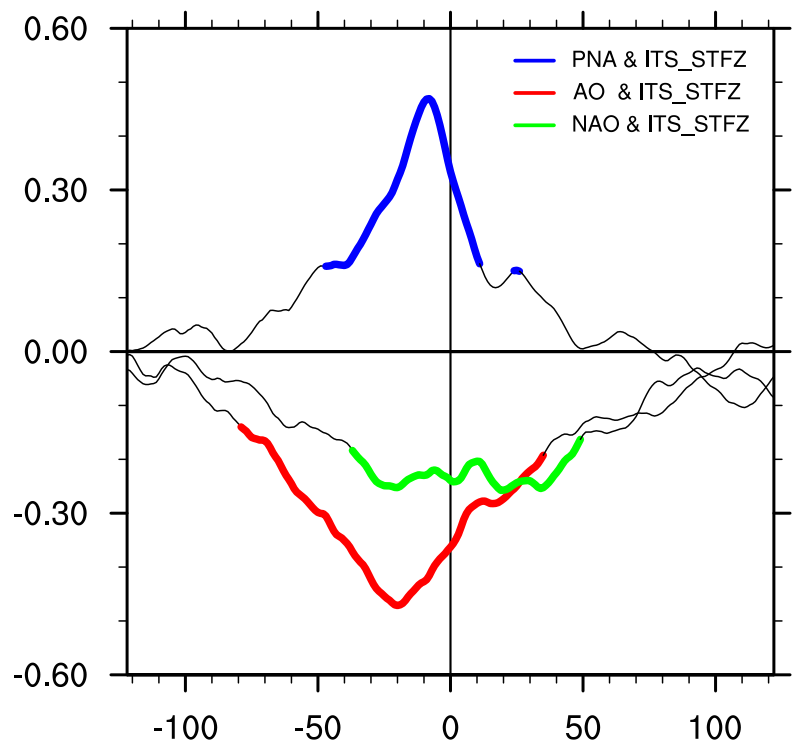

FIG. 3. Lead-lag cross-correlations between atmospheric mode (AO, PNA, NAO) indexes and wintertime intensity index of STFZ (ITS_STFZ). The $y$ axis is the correlation coefficient and the $x$ axis is lead and lag time in days, with negative (positive) values denoting that atmospheric indexes lead (lag) ITS_STFZ. The nongray lines denote correlation coefficient passing the $95 \%$ significance level, and red, blue, and green lines shows significant correlation, respectively, of the AO, PNA, and NAO with the ITS_STFZ.

and last for up to about 80,50 , and 40 days, respectively, and their associations with STFZ peak at 20-, 8-, and 20day leads, respectively. All of the negative-phase AO, positive-phase PNA, and negative-phase NAO anomalies have a long-lasting leading positive correlation with STFZ's intensity, but their lead times are not exactly the same. Hence, to further determine which atmospheric modes are major drivers for the STFZ intensity variation, we will discuss the relationships among those persistent modes below.

\section{b. Relationships among the persistent atmospheric modes}

Figure 4 presents pairwise comparisons of lead-lag correlations between the indexes of three atmospheric modes (AO, PNA, and NAO). The first-row graphs (Figs. 4a-c) show lead-lag autocorrelations between the daily indexes of any of the atmospheric modes and the respective wintertime daily indices, in which the correlation coefficients passing the $95 \%$ significance level are denoted by red. It can be found that the three atmospheric modes are all characterized by significant persistency. The AO, PNA, and NAO anomalies can sustain for roughly 110,30 , and 75 days, respectively, indicating their possible persistent connections with STFZ. The second-row graphs (Figs. 4d-f) show lead-lag 
(a) $\mathrm{AO}$ leadlag $\mathrm{AO}$

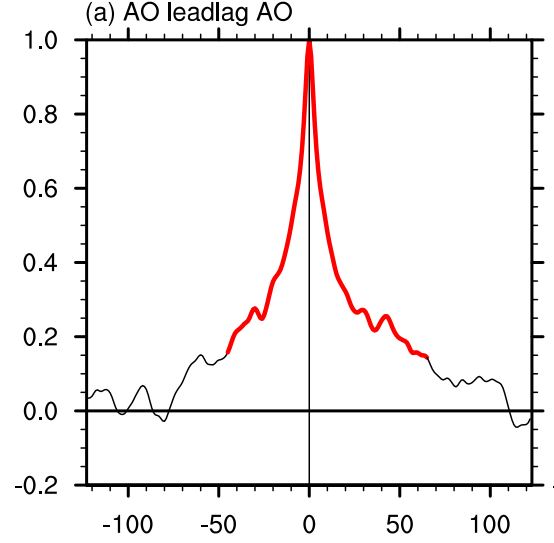

(d) AO leadlag PNA (b) PNA leadlag PNA

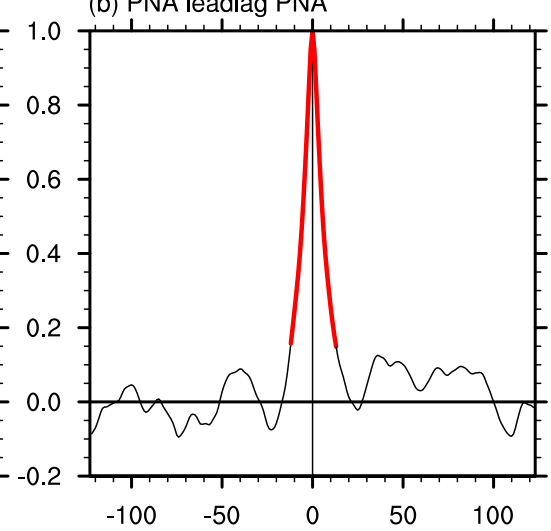

(e) AO leadlag NAO (c) NAO leadlag NAO

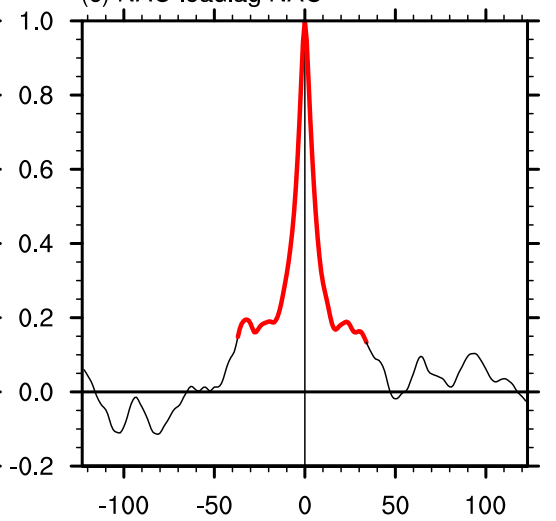

(f) NAO leadlag PNA
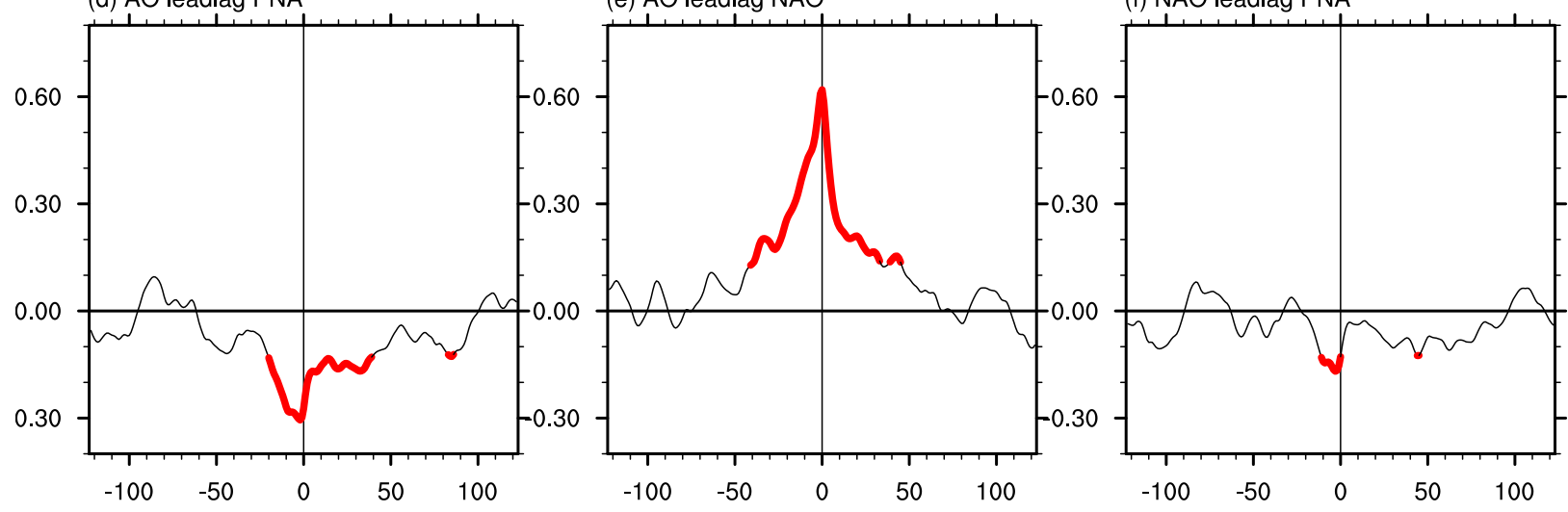

FIG. 4. (top) Lead-lag autocorrelations of the (a) AO, (b) PNA, and (c) NAO. (bottom) Lead-lag cross-correlations between atmospheric mode indexes of the (d) AO and PNA, (e) AO and NAO, and (f) NAO and PNA. The negative time leads indicate that the AO leads the PNA in (d) and the NAO in (e), and that the NAO leads the PNA in (f).

cross-correlations between the daily indexes of any two atmospheric modes. There is a significant negative correlation between the AO and PNA modes. It peaks when the AO leads the PNA roughly by 2 days, indicating that a negative-phase AO tends to induce a positive-phase PNA anomaly development. It is interesting that the reliable cross-correlation between the $\mathrm{AO}$ and NAO is positive with maximum value at day 0 , like a distribution of autocorrelation, indicating their inphase relationship. The correlation between the NAO and PNA is similar to that between the AO and PNA, but with smaller values.

Combining the results of Figs. 2-4, we can derive that persistent negative-phase AO and positive-phase PNA anomalies tend to cause the enhancement of STFZ, starting at up to 80 and 50 days ahead, respectively, and peaking at 20 and 8 days ahead, respectively. Moreover, the fact that the $\mathrm{AO}$ and PNA have a negative correlation peaking when the AO leads the PNA by 2 days suggests a forcing of the AO on the PNA. The NAO anomaly varies in phase with the AO, since it correlates with ITS_STFZ or PNA just as the AO does. That is to say, although the
NAO correlates with the STFZ, it seems more like a regional representation of the zonally symmetric, annular AO mode (Thompson and Wallace 1998, 2000; Ambaum et al. 2001). Therefore, the relationship between the AO and PNA anomalies is further examined below in order to figure out how they interact with each other and how they further influence the STFZ, focusing particularly on the time nodes of days $-20,-8,-2$, and 0 .

The left panels of Fig. 5 show regressed horizontal distribution of wintertime lower-tropospheric atmospheric baroclinicity anomalies upon the AO index at different lead times. The baroclinicity is represented by the maximum Eady growth rate, which is defined as $\sigma_{\mathrm{BI}}=0.31 f|\partial \mathbf{V} / \partial z| / N$ (Lindzen and Farrell 1980; Hoskins and Valdes 1990). From day -20 to day 0 (i.e., the AO index leads the baroclinicity anomaly by 20 to 0 days), AO-regressed negative anomalies in baroclinicity gradually get stronger over the midlatitude western-to-central North Pacific around $40^{\circ} \mathrm{N}$ where there is a climatological baroclinic region, roughly marked with a red rectangular box (shown in the left panels of Fig. 5). The climatological baroclinic region has been shown to have a close link with transient eddy activities, storm tracks, and jet 

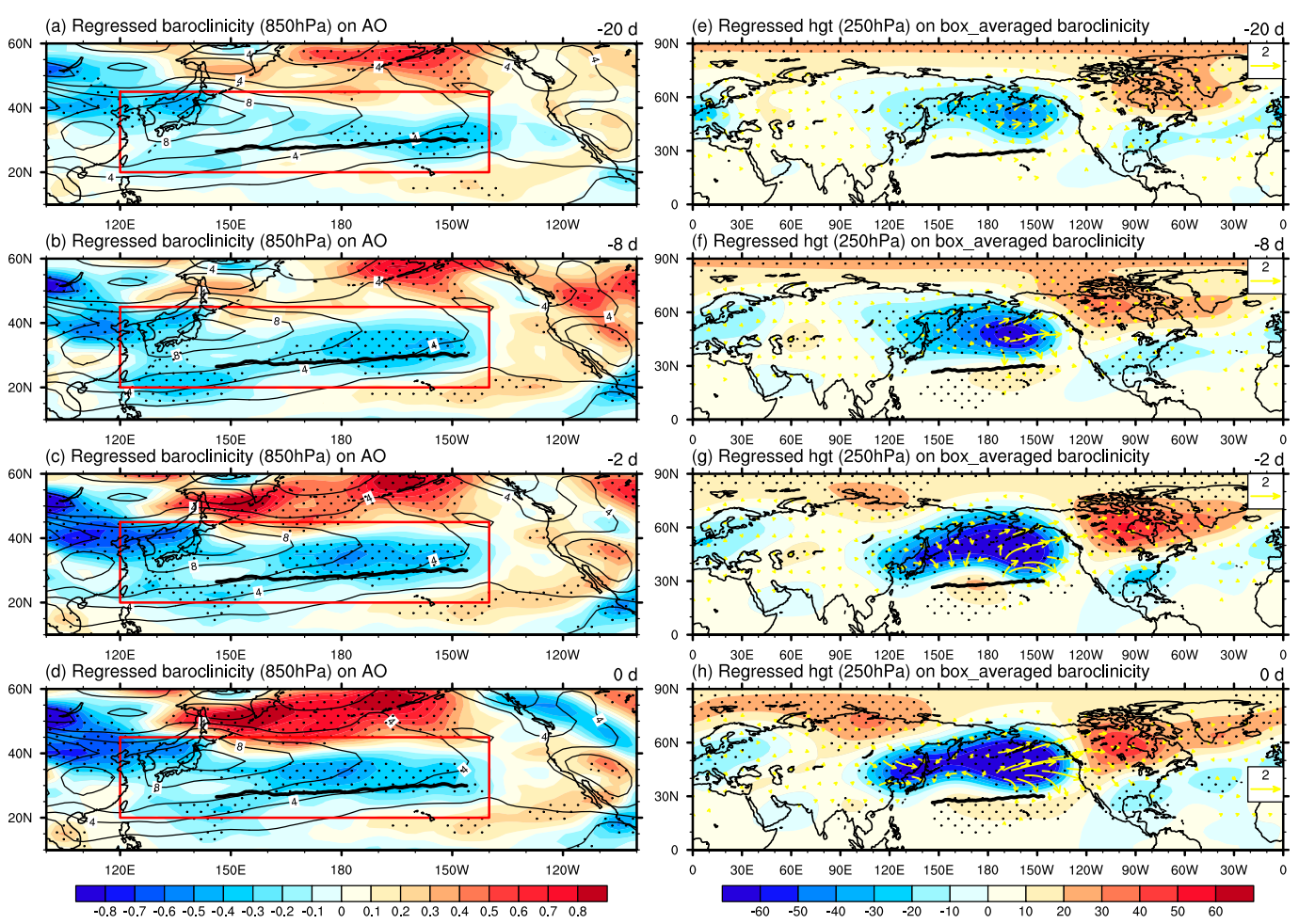

FIG. 5. As in Fig. 2, but for the regressions of (left) 850 -hPa wintertime baroclinicity anomalies (day ${ }^{-1}$; shaded) upon the standardized AO index and (right) 250-hPa wintertime geopotential height anomalies (m; shaded) upon the red rectangular box area-averaged standardized baroclinicity index, with the respective index leading baroclinicity or geopotential height by (a),(e) 20 , (b),(f) 8 , (c),(g) 2 , and (d),(h) 0 days. The contours in the left panels denote climatological 850 -hPa baroclinicity $\left(\right.$ day $\left.^{-1}\right)$. The vectors in the right panels denote the corresponding wave activity flux $\left(\mathrm{m}^{2} \mathrm{~s}^{-2}\right)$. The red box ranges from $20^{\circ}$ to $45^{\circ} \mathrm{N}$ and $120^{\circ} \mathrm{E}$ to $140^{\circ} \mathrm{W}$.

streams in the North Hemisphere (Sampe et al. 2010; Taguchi et al. 2009; Fang and Yang 2016). Our results indicate that a negative-phase AO tends to induce an intensified low-level atmospheric baroclinicity just in the climatological baroclinic region. Furthermore, by regressing geopotential height upon the red box areaaveraged baroclinicity index, it is found from the right panels of Fig. 5 that the intensified baroclinicity in the red box region favors a PNA-like pattern development, which is especially significant at day -2 (i.e., when geopotential height lags baroclinicity by 2 days). The detailed dynamical process for how the AO can affect the PNA via altering baroclinicity is discussed below.

As a result, the negative-phase AO-induced stronger lowlevel atmospheric baroclinicity over the midlatitude North Pacific tends to cause more synoptic-scale transient eddy (TE) activities, which can systematically transport and redistribute the heat and momentum flux, contributing to midlatitude atmospheric circulation anomalies. Recent studies on midlatitude air-sea interaction found that, compared to the diabatic heating and TE heat forcing, the TE dynamical (vorticity) forcing plays a major role in enhancing and maintaining the equivalent barotropic geopotential height anomalies over the midlatitude North Pacific (Fang and Yang 2016; Wang et al. 2017). Following Fang and Yang (2016), the tendency of geopotential height anomaly induced by the TE vorticity forcing anomaly can be diagnosed via the derivation relationship of the quasigeostrophic potential vorticity (QGPV) equation

$$
\left[\frac{1}{f} \nabla^{2}+f \frac{\partial}{\partial p}\left(\frac{1}{\bar{\sigma}_{1}} \frac{\partial}{\partial p}\right)\right]\left(\frac{\partial \Delta \bar{\Phi}}{\partial t}\right) \propto \Delta \bar{F}_{\text {eddy }}
$$

where the overbar denotes the time mean (low-frequency flow) and $\Delta$ denotes the anomaly from its climatology; $\Phi$ is the geopotential height and $\sigma_{1}$ the static stability parameter. The potential vorticity source on the right-hand side of Eq. (2) represents the TE vorticity forcing anomaly, $\Delta \bar{F}_{\text {eddy }}$, that is, $F_{3}$ used in Fang and Yang (2016). The TE vorticity forcing, which is determined by the convergence of vorticity flux transported by TE, is expressed as

$$
F_{\text {eddy }}=-\nabla_{h} \cdot\left(\mathbf{V}^{\prime} \boldsymbol{s}^{\prime}\right)
$$



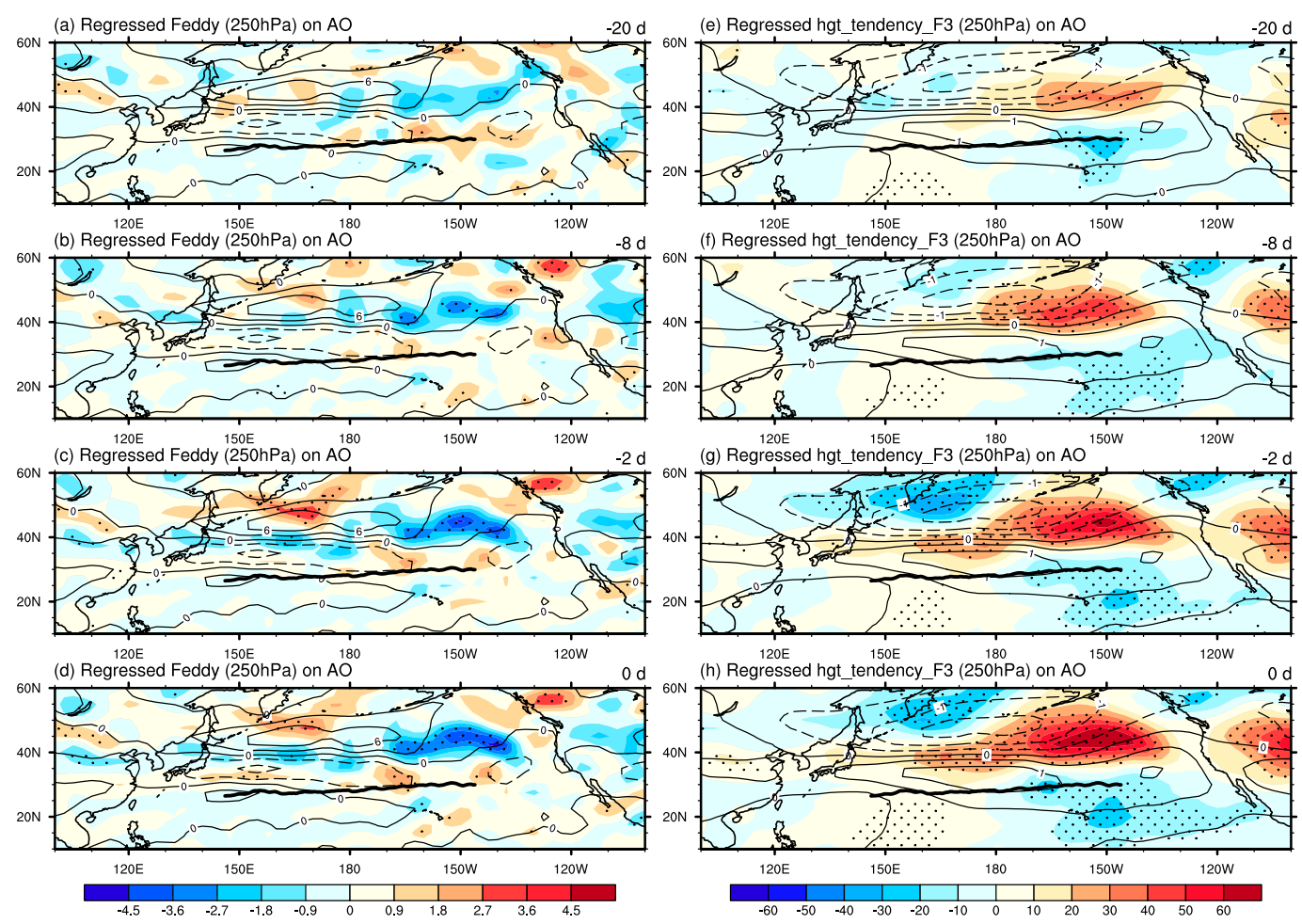

FIG. 6. As in Fig. 2, but for the regressions of wintertime (left) transient eddy (TE) vorticity forcing anomalies $\left(10^{-11} \mathrm{~s}^{-2}\right.$; shaded) and (right) geopotential height tendency anomalies $\left(10^{-3} \mathrm{~m}^{2} \mathrm{~s}^{-3}\right.$; shaded) induced by the TE vorticity forcing anomalies, respectively, upon the standardized AO index, with the AO index leading TE vorticity forcing or geopotential height tendency by (a),(e) 20, (b),(f) 8 , (c),(g) 2, and (d),(h) 0 days. Note that the contours denote their respective climatological values.

where the prime denotes 2-8-day synoptic-scale TE, $\mathbf{V}$ is the horizontal wind vector, and $s$ the vertical vorticity. With the successive overrelaxation (SOR) method, the tendency of geopotential height anomaly induced by TE vorticity forcing anomaly is numerically calculated according to Eq. (2).

As in Figs. 5 and 6 shows the regressed anomalies of TE vorticity forcing (left panels) and geopotential height tendency only induced by TE vorticity forcing (right panels) upon the AO index from day -20 to day 0 . Both the TE vorticity forcing and geopotential height tendency anomalies display a dipole pattern with opposite signs across $40^{\circ} \mathrm{N}$ where the climatological baroclinic region locates (see left panels of Fig. 5). The positive TE vorticity forcing anomalies north of $40^{\circ} \mathrm{N}$ (left panels of Fig. 6) correspond to the appearance of the negative geopotential height tendency anomalies (right panels of Fig. 6) while the AO anomaly is in a negative phase. Moreover, these regressed anomalies (shaded) are in phase with their corresponding climatological values (contours), suggesting a strengthening effect. In other words, a negative-phase $\mathrm{AO}$ anomaly tends to produce a positive TE vorticity forcing anomaly in the central-to- eastern North Pacific north of $40^{\circ} \mathrm{N}$, which can further induce a local negative geopotential height tendency anomaly there. The negative geopotential height tendency anomaly favors significant development of local negative geopotential height anomaly, that is, a center of action of PNA pattern over the Aleutian region, as shown in the right panels of Fig. 5. By calculating the wave activity flux (Takaya and Nakamura 2001), we find that there exists significant energy dispersion downstream of the low-frequency wave originating from the North Pacific center, as shown with vectors in the right panels of Fig. 5. It is the energy dispersion downstream that excites the development of the PNA pattern.

In accordance with the negative phase of the $\mathrm{AO}$, an equivalent barotropic negative geopotential height anomaly over the midlatitude North Pacific (Fig. 5) is associated with an intensified westerly wind on its south edge (Fig. 7). The regressed positive anomalies of zonal wind are in phase with its climatology, suggesting a strengthening effect of westerly wind on the STFZ. When the intensified westerly wind leads the STFZ by about 8 days, their positive connection becomes the most evident (Figs. 7c,g), 

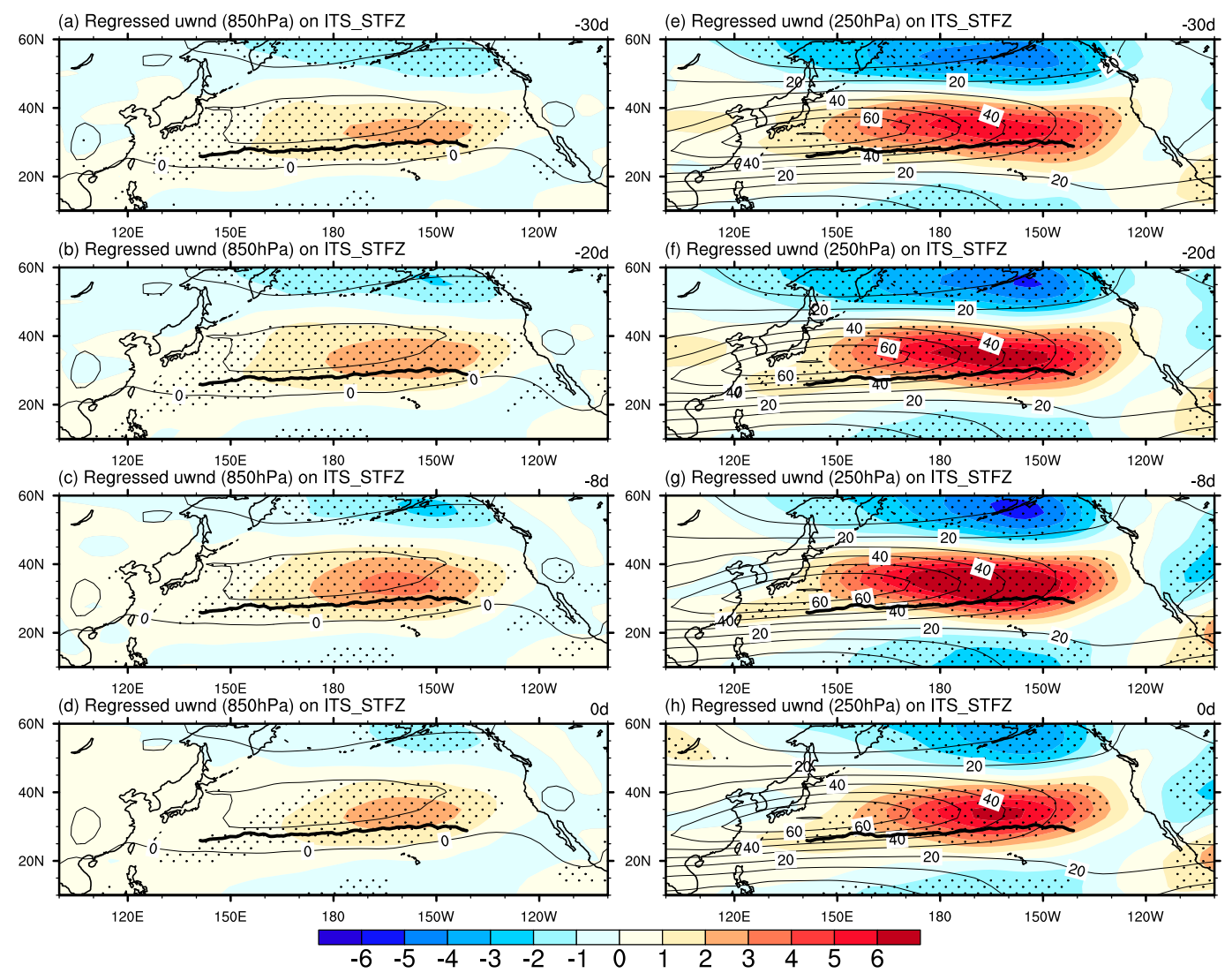

FIG. 7. As in Fig. 2, but for the regressions of (left) 850- and (right) 250-hPa zonal wind speed anomalies ( $\mathrm{m} \mathrm{s}^{-1}$; shaded) upon wintertime standardized intensity index of the STFZ (ITS_STFZ), with zonal wind leading the ITS_ STFZ by (a),(e) 30, (b),(f) 20, (c),(g) 8, and (d),(h) 0 days. Note that the contours denote their respective climatological values.

corresponding to the timing when PNA has the most significant lead relationship with the STFZ (Fig. 3).

Based on above analysis, the subseasonal time-scale negative-phase AO anomaly is indicated to persistently enhance the wintertime atmospheric baroclinicity in the North Pacific climatological baroclinic region, which tends to excite more TE activities. Via the TE vorticity forcing, an equivalent barotropic geopotential low anomaly is promoted and propagates downstream through a great circle wave train path, generating a PNA-like anomaly pattern. Through atmospheric internal transient wave feedback onto the mean flow process as well as the lowfrequency wave downstream energy dispersion process, the regional PNA mode is triggered by $\mathrm{AO}$, and is further intensified and embedded in the annular AO mode. Furthermore, the coexistence of AO and PNA anomalies is accompanied with intensified equivalent geopotential low and westerly wind anomalies. Down to nearly the sea surface, they are presented as the intensifications of Aleutian low and surface westerly wind, which peak at an 8-day lead, thus preconditioning a persistent surface atmospheric forcing on the ocean in the STFZ. Specifically, this atmospheric forcing on STFZ is proved to be not stochastic, but persistent on a subseasonal time scale.

\section{Mechanisms for atmospheric impact on STFZ}

Many previous studies conducted oceanic mixed layer heat budget diagnoses and revealed physical approaches of the atmospheric impact on the midlatitude SST variations (Li et al. 2002; Kwon et al. 2010; Foltz et al. 2013). In this section, detailed processes of surface atmospheric forcing associated with those anomalous atmospheric modes on STFZ are diagnosed. The near-surface westerly wind speed indeed has a positive correlation with STFZ's intensity (Figs. 8a,b). Prior to the STFZ enhancement at least one month ahead, intensified surface westerly wind exists north of STFZ, which drives the upper-layer oceanic current and enhances southward Ekman current (Figs. 8c,d), acting to generate a negative 

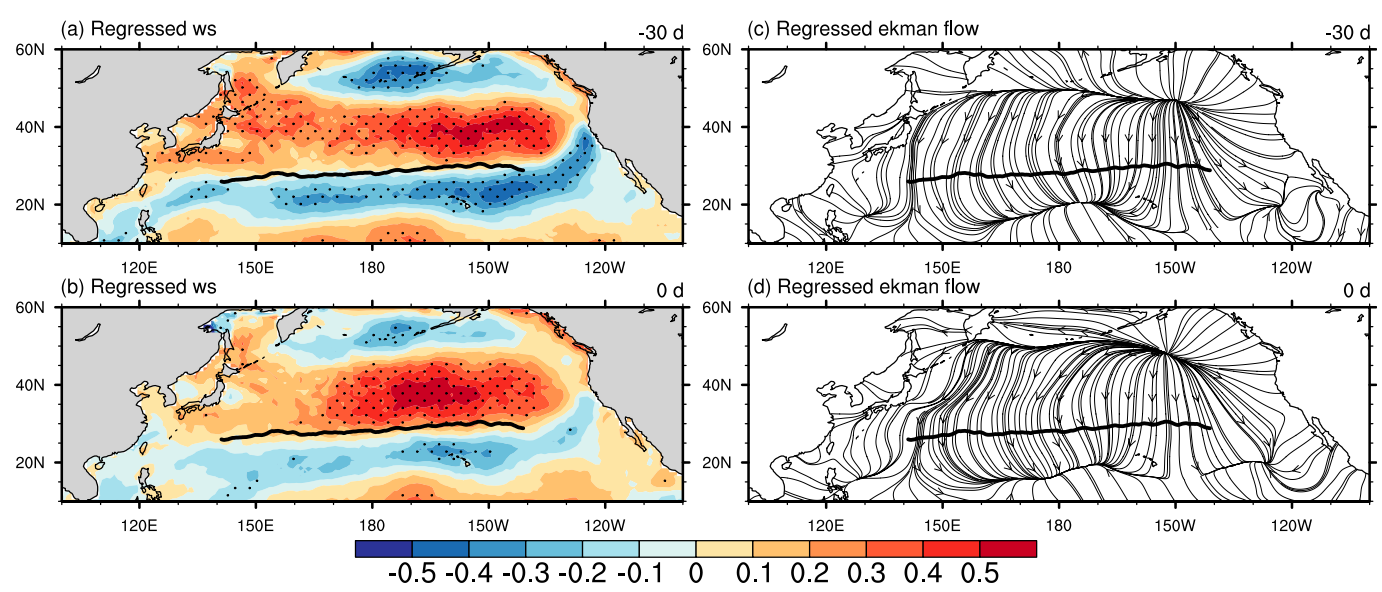

FIG. 8. As in Fig. 2, but for (left) the surface wind speed ( $\mathrm{m} \mathrm{s}^{-1}$; shaded) and (right) Ekman flow (streamline) anomalies, leading the wintertime standardized intensity index of the STFZ (ITS_STFZ) by (a),(c) 30 and (b),(d) 0 days.

SST anomaly north of STFZ. Besides the Ekman flow's advection, intensified Ekman pumping, which is driven by a positive wind stress curl anomaly, also plays a role in such a SST cooling. Therefore, both the oceanic dynamical processes favor amplifying the meridional cross-frontal SST gradient (i.e., the STFZ's intensity).

Besides the dynamical forcing, the westerly-related thermal forcing, which is represented by the air-sea interface heat flux, also is at work. According to previous studies (Yu and Weller 2007; Yu et al. 2008; Wang et al. 2018), the latent heat (LH) and sensible heat (SH) flux anomalies are largely determined by the near-surface wind speed anomaly and the sea-air difference anomaly of specific humidity (or temperature). Their respective contributions to the upward $\mathrm{LH}$ (or $\mathrm{SH}$ ) flux anomaly can be linearly decomposed and quantitatively calculated as

$$
\begin{aligned}
& \Delta \mathrm{LHF} \uparrow=\rho L_{e} C_{e}\left[\bar{U}^{c} \Delta\left(q_{s}-q_{a}\right)+\Delta U\left(\bar{q}_{s}^{c}-\bar{q}_{a}^{c}\right)\right], \\
& \Delta \mathrm{SHF} \uparrow=\rho C_{p} C_{h}\left[\bar{U}^{c}\left(\Delta T_{s}-\Delta T\right)+\Delta U\left(\bar{T}_{s}^{c}-\bar{T}_{a}^{c}\right)\right],
\end{aligned}
$$

where $\rho$ is the air density, $L_{e}$ the latent heat of evaporation, $C_{e}$ and $C_{h}$ the turbulent exchange coefficients for latent heat flux and sensible heat flux, respectively, and $C_{p}$ the specific heat capacity; $U$ is the surface wind speed, and $q_{s}-q_{a}$ and $T_{s}-T_{a}$ represent the sea-air differences of specific humidity and temperature, respectively. The overbar denotes climatological mean and $\Delta$ the anomaly from the mean.

By calculating the decomposition components of $\mathrm{LH}$ and SH anomalies and regressing them upon ITS_STFZ, the relationships between heat fluxes and STFZ's intensity are quantitatively investigated (Figs. 9-11). The regressed LH anomaly is characterized by a dipole distribution around STFZ. The positive (negative) anomaly on the north (south) side stands for more (less) LH loss from ocean to atmosphere; see Figs. 9a-d. By comparing the regressed total LH flux anomaly with its components from wind speed anomaly in Figs. 9e-h and from the sea-air specific humidity difference anomaly in Figs. 9i-1, it is found that the wind speed anomaly plays a major role in taking more (less) LH from the ocean north (south) of STFZ, leading to the formation of LH's dipole anomaly pattern as shown in Figs. 9a-d. Under the influence of the LH anomaly, the cross-frontal meridional SST gradient is reinforced, particularly at day -8 . The STFZ-related SH anomaly (Fig. 10) is found to be similar to, but relatively weaker than, that of LH anomaly (Fig. 9). By comparing the regressed total SH flux anomaly with its components from wind speed anomaly (Figs. 10e-h) and from the sea-air temperature difference anomaly (Figs. 10i-1), it is found that the latter makes a major contribution to the total $\mathrm{SH}$ anomaly. Furthermore, such a sea-air temperature difference anomaly is mainly determined by the surface air temperature (SAT) anomaly rather than the surface sea temperature (SST) anomaly in Fig. 11, for the reason that even though SAT and SST are both colder north of STFZ, the SAT is much colder than the SST beneath. The temperature difference between SST and SAT is positive, meaning more upward SH flux is transferred from ocean to atmosphere north of the STFZ (Figs. 10i-1). Through the above processes, the SH anomaly dominated by sea-air temperature difference also favors the enhancement of the cross-frontal SST gradient (i.e., the STFZ's intensity).

Further, a quantitative SST budget analysis is made to estimate the relative contributions of different physical processes in terms of the following linearized equation 

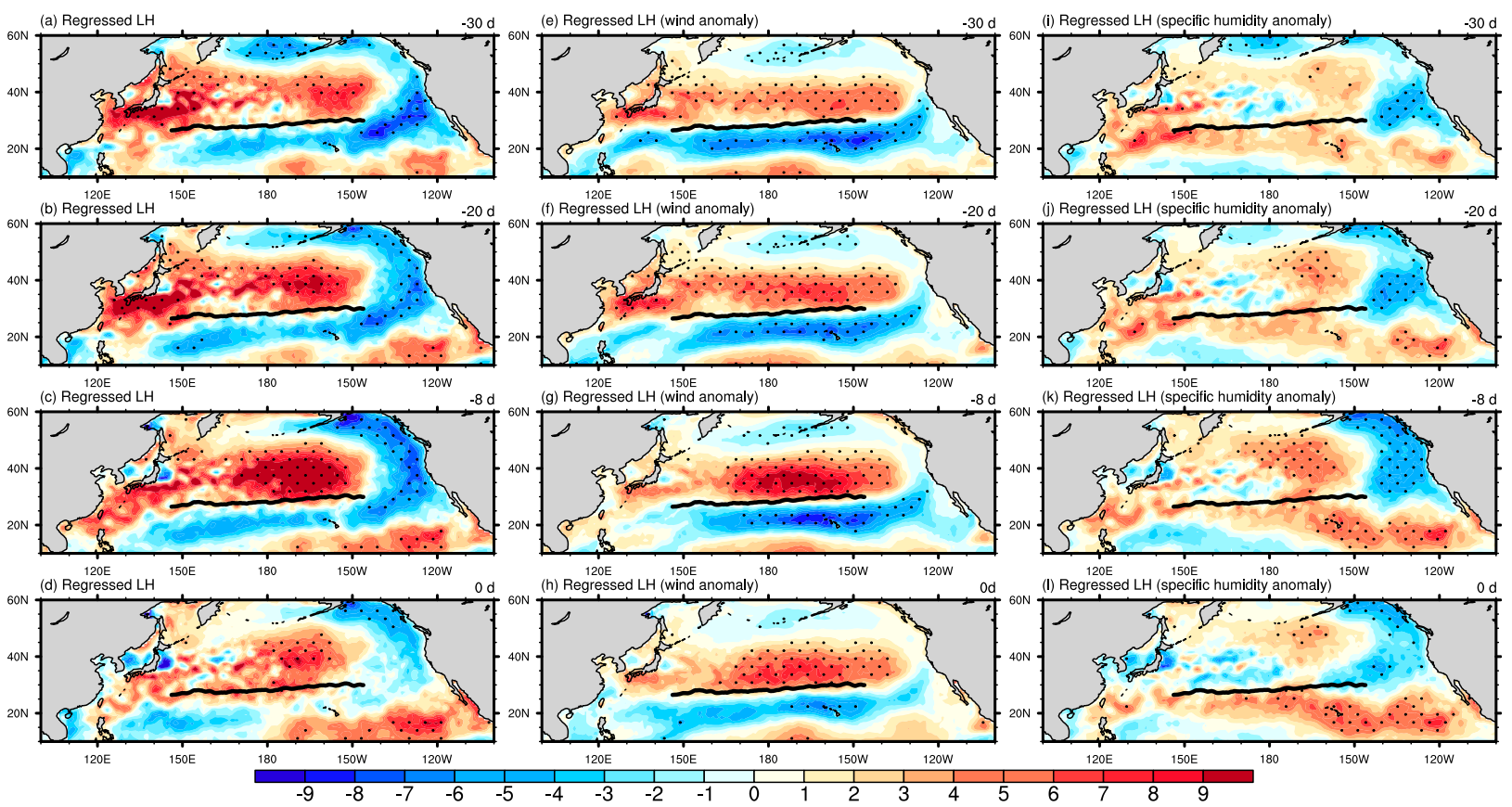

FIG. 9. As in Fig. 2, but for the anomalies ( $\mathrm{W} \mathrm{m}^{-2}$; shaded) of (left) latent heat (LH) flux, (center) LH flux induced by surface wind speed anomaly, and (right) LH flux induced by sea-air specific humidity difference anomaly, leading the wintertime standardized intensity index of the STFZ (ITS_STFZ) by (a),(e),(i) 30, (b),(f),(j) 20 days, (c),(g),(k) 8, and (d),(h),(l) 0 days.

(Fang and Yang 2016; Foltz et al. 2013; Li et al. 2002; Wang et al. 2012):

$$
\frac{\partial \Delta T}{\partial t}=-\Delta v \frac{\partial \bar{T}^{c}}{\partial y}-\Delta w_{e} \frac{\partial \bar{T}^{c}}{\partial z}+\frac{\Delta Q}{\rho C_{p} H},
$$

where the overbar denotes climatological mean, $\Delta$ is the regressed anomaly upon ITS_STFZ, $v$ is the meridional ocean current speed, $w_{e}$ the vertical Ekman pumping velocity, $Q$ the net downward surface heat flux, $H$ the mixed layer depth taken as $100 \mathrm{~m}, T$ the sea temperature in the mixed layer, $\rho$ the water density, and $C_{p}$ the specific heat of seawater. The three right-hand-side terms determining the SST tendency in Eq. (6) indicate the meridional temperature advection, vertical Ekman pumping, and net surface heat flux exchange, respectively.

Figure 12 shows horizontal distributions of regressed SST tendency anomalies induced by meridional and vertical temperature advection and net surface heat flux upon the standardized ITS_STFZ. From 1-month lead to the simultaneous time, all of these three terms can make contributions to the SST negative anomaly north of the STFZ in the central North Pacific. Among them, the meridional temperature advection (Figs. 12a,b) induced by southward Ekman current anomaly (Figs. 8c,d) and the net surface heat flux (Figs. 12e,f) make major and secondary contributions to the SST tendency anomalies, respectively, while the vertical temperature advection (induced by Ekman pumping) (Figs. 12c,d) makes a relatively small contribution.

Hence, the negative-phase AO- and positive-phase PNAinduced surface westerly enhancement primarily drives a stronger southward Ekman current, which can generate a negative SST anomaly north of the STFZ. On the other hand, the increased surface wind speed can affect the surface air-sea heat flux exchanges by causing more (less) heat loss from ocean to atmosphere, and finally induce a negative (positive) SST anomaly north (south) of STFZ. Through both dynamical and thermal processes, the cross-frontal meridional SST gradient is thus increased, ultimately followed by the enhancement of the STFZ.

\section{Concluding remarks}

There are two remarkable basin-scale oceanic frontal zones lying in the midlatitude North Pacific around $30^{\circ}$ and $40^{\circ} \mathrm{N}$, called the subtropical frontal zone (STFZ) and subarctic frontal zone (SAFZ), respectively, both featuring large meridional SST gradients, especially in winter. Their related SST anomaly patterns are found to be closely associated with two typical midlatitude SST anomaly modes, the PDO and NPGO, respectively. Since the PDO is the principal signature of interdecadal variability in the North Pacific air-sea system, the basin-scale STFZ is a key region for midlatitude air-sea 

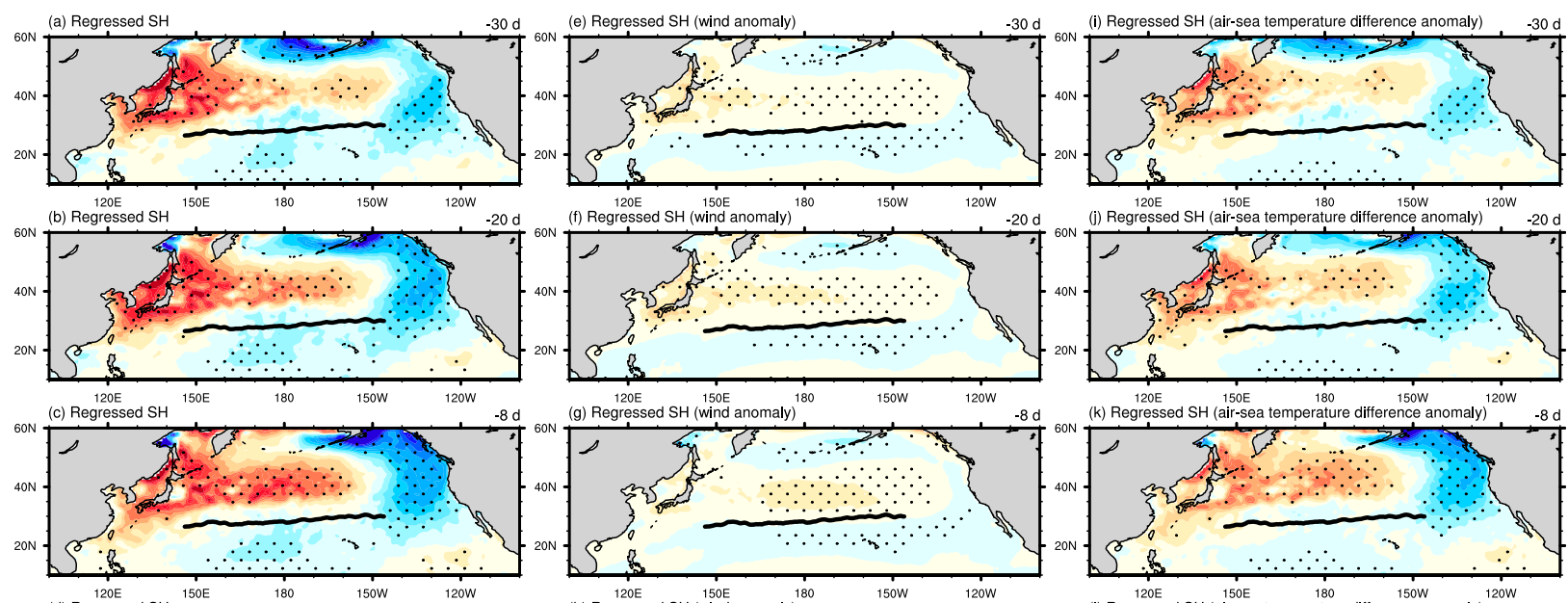

(k) Regressed SH (air-sea temperature difference anomaly) $120 \mathrm{~W}$

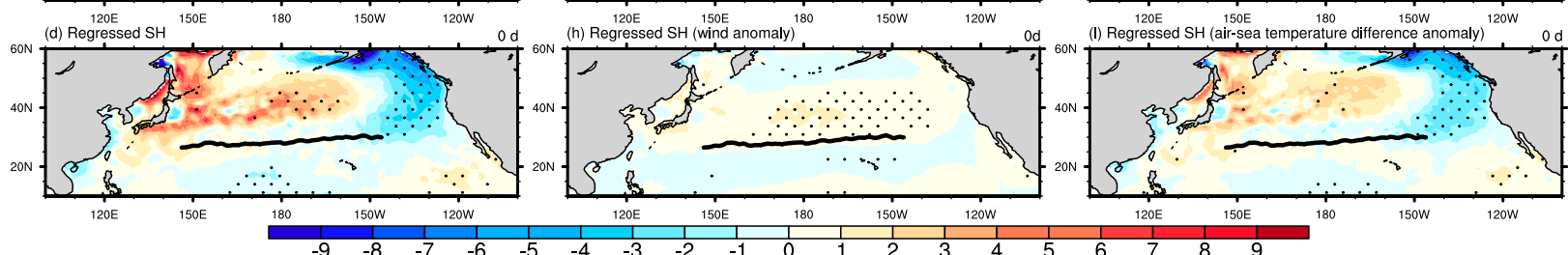

FIG. 10. As in Fig. 2, but for the anomalies ( $\mathrm{W} \mathrm{m}^{-2}$; shaded) of (left) sensible heat (SH) flux, (center) SH flux induced by surface wind speed anomaly, and (right) SH flux induced by sea-air temperature difference anomaly, leading the wintertime standardized intensity index of the STFZ (ITS_STFZ) by (a),(e),(i) 30, (b),(f),(j) 20, (c),(g),(k) 8, and (d),(h),(l) 0 days.

interaction in the North Pacific. However, previous studies considered midlatitude sea surface temperature variabilities as a response to atmospheric stochastic forcing. With reanalysis and observational data, this study investigates what kinds of atmospheric anomalies drive the wintertime North Pacific STFZ intensity variation and associated influencing processes.

By conducting lead-lag regressions of atmospheric geopotential height anomalies upon the intensity index of STFZ (ITS_STFZ), we found three typical atmospheric anomaly modes (i.e., the AO, PNA, and NAO modes), which are closely associated with the wintertime intensity variation of STFZ. Lead-lag cross-correlations between these atmospheric mode indexes and ITS_STFZ also verify the existence of connections between these atmospheric modes and STFZ's intensity. Prior to the STFZ enhancement, there exist significant atmospheric anomalies characterized by a negative-phase $\mathrm{AO}$ and a positive-phase PNA pattern, by up to 80- and 50-day leads, peaking on day -20 and day -8 , respectively. Both the AO and PNA pattern are low-frequency atmospheric modes that can sustain for about 110 and 30 days, respectively, and provide a persistent atmospheric forcing on the STFZ. Moreover, there is a significant negative correlation between the AO and PNA pattern, which peaks on day -2 when the AO leads the PNA pattern. Both the indirect correlations in which ITS_STFZ is regarded as an object of reference and the direct pairwise correlations between atmospheric indexes suggest an $\mathrm{AO}$ forcing on the PNA. Although the NAO anomaly correlates with the STFZ, the NAO varies in phase with the $\mathrm{AO}$ and seems more like a regional representation of the latter.

Due to strong internal chaotic variabilities in the midlatitude atmosphere, the atmospheric forcing on ocean is generally believed to be of high frequency and stochastic. However, this paper provides evidence that the atmospheric forcing on the STFZ is characterized by a longlasting AO anomaly, which is persistent with low-frequency subseasonal time scales rather than stochastic.

It is revealed that a negative-phase AO anomaly is beneficial for an enhanced low-level atmospheric baroclinicity in the climatological baroclinic region over the midlatitude North Pacific, thereby inducing more synoptic-scale transient eddy activities. Fang and Yang (2016) identified the indispensable role of atmospheric transient eddy activities in the midlatitude unstable air-sea interaction, and pointed out that the atmospheric transient eddy vorticity forcing dominantly contributes to the equivalent barotropic westerly wind anomaly. The role is also confirmed in this paper. With the negative phase, the persistent AO exerts impacts on the low-level atmospheric baroclinicity, and more atmospheric transient eddy activities over the North Pacific tend to induce a negative geopotential height tendency anomaly north of the STFZ, via the atmospheric transient eddy vorticity forcing mechanism. This low geopotential height anomaly propagates downstream through a great 

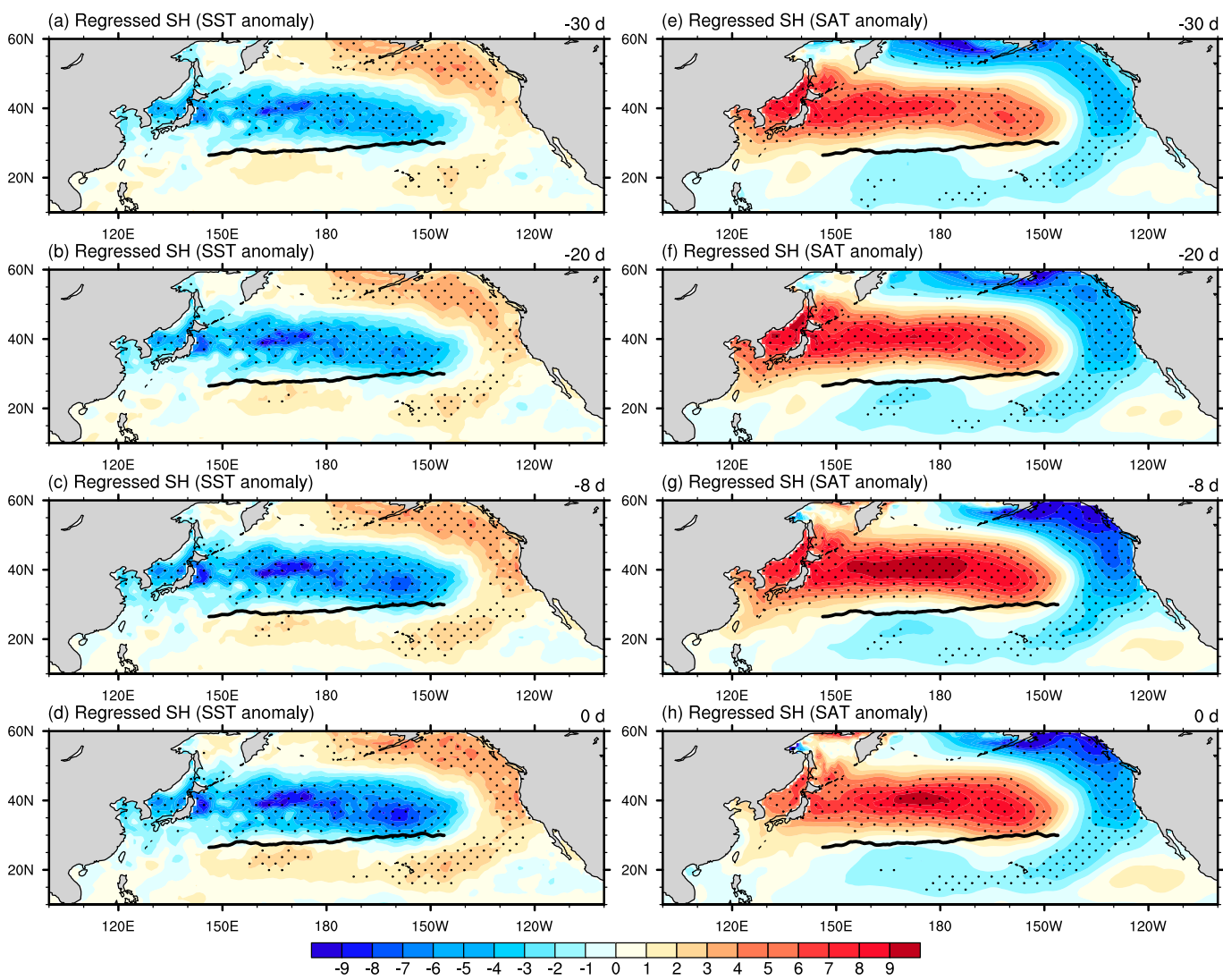

FIG. 11. As in Fig. 2, but for the SH flux anomalies ( $\mathrm{W} \mathrm{m}^{-2}$; shaded) induced by (left) SST anomalies and (right) surface air temperature (SAT) anomalies, leading the wintertime standardized intensity index of the STFZ (ITS STFZ) by (a),(e) 30, (b),(f) 20, (c),(g) 8, and (d),(h) 0 days.

circle route, forming a PNA-like anomaly pattern. Through such a synoptic wave-low-frequency flow feedback, the regional PNA mode is further strengthened and embedded in the annular AO mode, resulting in an intensification of low geopotential height anomaly north of STFZ in the North Pacific. According to the quasigeostrophic theory, the low geopotential height anomaly, which features an equivalent barotropic structure, is accompanied with barotropic westerly wind anomaly locating at its southern flank. Therefore, the Aleutian low and surface westerly wind are enhanced, thus generating a direct atmospheric forcing on STFZ.
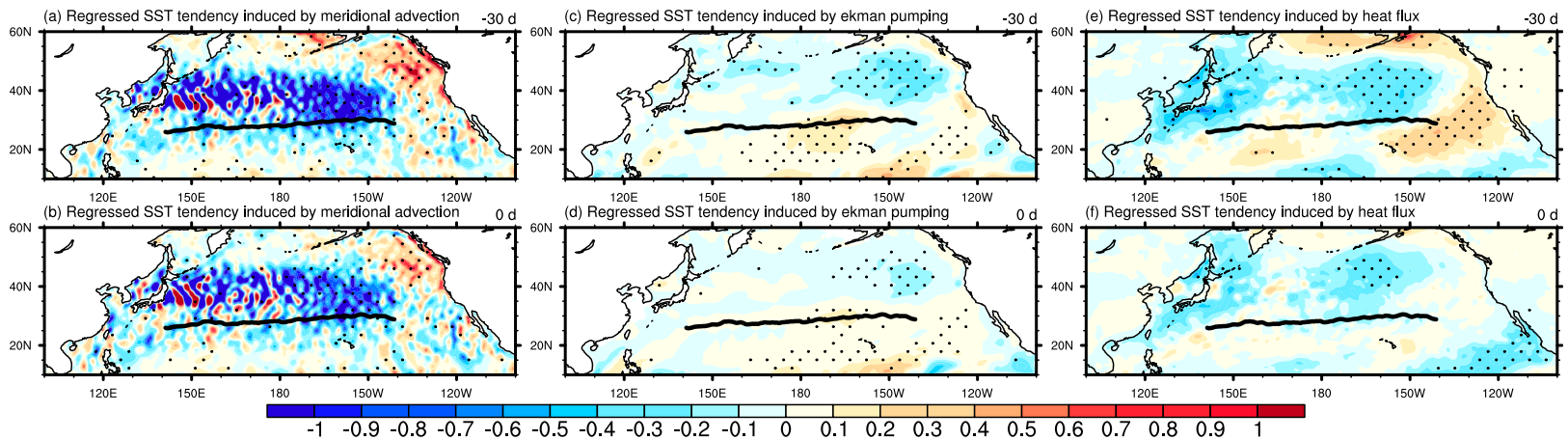

FIG. 12. As in Fig. 2, but for the SST tendency anomalies $\left(10^{-7} \mathrm{~K} \mathrm{~s}^{-1}\right.$; shaded) induced by (left) meridional advection, (center) Ekman pumping, and (right) surface heat flux, leading the wintertime standardized intensity index of the STFZ (ITS_STFZ) by (a),(c),(e) 30 and (b),(d),(f) 0 days. 
The intensified surface westerly anomaly tends to drive a stronger southward Ekman current. Also, the enhanced Aleutian low provides a positive wind stress curl anomaly, which causes an enhanced Ekman pumping. Meanwhile, the westerly wind anomaly also affects the net heat flux exchanges at air-sea interface. The latent heat (LH) and sensible heat (SH) flux anomalies are linearly decomposed into two components determined by the wind speed anomaly and by the sea-air difference anomaly, respectively. It is found that the LH flux anomaly is dominated by the surface wind anomaly, while the SH flux anomaly is dominated by the sea-air temperature difference anomaly. The enhanced surface westerly wind acts to lead to more LH loss from ocean to atmosphere north of STFZ. Meanwhile, because the cold surface air temperature (SAT) anomaly, which dynamically corresponds to the equivalent barotropic low geopotential height anomaly, is much lower than the cold SST anomaly underneath, the sea-air temperature difference anomaly gives rise to more $\mathrm{SH}$ loss from ocean to atmosphere north of STFZ. Both processes favor more oceanic heat loss and thus are indicative of cold SST anomaly development north of the STFZ. Although the westerly wind anomaly can affect the regional SST variation through dynamical processes (southward Ekman current and upward Ekman pumping) and thermal processes (surface heat flux exchanges), a quantitative SST budget diagnosis demonstrates that the horizontal advection due to the Ekman current makes a dominant contribution to the SST variation, while the surface net heat flux makes a secondary contribution. The contribution of Ekman pumping is relatively weak. Therefore, with combined contributions from those three enhanced westerlyinduced processes, the negative SST anomaly and crossfrontal meridional SST gradient are strengthened, ultimately giving rise to the enhancement of STFZ.

This paper discusses about the atmospheric anomalies that determine the intensity variation of the wintertime basin-scale STFZ in the North Pacific. Results indicate that it is the AO that induces persistent (nonstochastic) atmospheric forcing on STFZ on a subseasonal time scale, in which the PNA mode that is excited by AO through synoptic waves feedback onto low-frequency flow plays a key role. We notice that both the AO and PNA pattern are basically internal modes in the midand high-latitude atmosphere. The appearance of those modes can be either independent or associated, and even coupled with the underneath ocean. As found in this study, it is interesting that the persistent $\mathrm{AO}$ can trigger a delayed PNA pattern development through internal atmospheric dynamics, which is central to the STFZ intensity variation. However, it is still mysterious whether or not those PNA patterns independent of AO can have impacts on the STFZ. Moreover, we may ask whether or not there exists the possibility that the persistent lifespan in winter of AO and PNA modes may be supported by the ocean, and the atmospheric forcing may be somehow influenced by the oceanic feedback. Therefore, a complete air-sea interaction loop on the low-frequency subseasonal time scales remains unclear. The forcing of oceanic front variabilities on the atmosphere also needs further investigation. How can the underlying oceanic front affect the low-level atmospheric baroclinicity as well as the transient eddy activities and atmospheric circulation? What is the interaction between the oceanic front and the atmosphere? Besides, observational analyses show that the STFZ and SAFZ in the North Pacific are meridionally located closely to each other and can interfere with each other, which makes above questions more complicated. All of these issues deserve to be examined in future studies.

Acknowledgments. This work is jointly supported by the National Natural Science Foundation of China (Grant 41621005) and the National Key R and D Program of China (Grant 2018YFC1505902). We are grateful for support from the Jiangsu Collaborative Innovation Center for Climate Change. We appreciate the constructive comments from three anonymous reviewers who helped improve the manuscript.

\section{REFERENCES}

Ambaum, M. H., B. J. Hoskins, and D. B. Stephenson, 2001: Arctic Oscillation or North Atlantic Oscillation? J. Climate, 14, 34953507, https://doi.org/10.1175/1520-0442(2001)014<3495: AOONAO $>2.0 . \mathrm{CO} ; 2$.

Banzon, V., T. M. Smith, T. M. Chin, C. Liu, and W. Hankins, 2016: A long-term record of blended satellite and in situ sea-surface temperature for climate monitoring, modeling and environmental studies. Earth Syst. Sci. Data, 8, 165-176, https:// doi.org/10.5194/essd-8-165-2016.

Carton, J. A., G. Chepurin, X. Cao, and B. Giese, 2000: A simple ocean data assimilation analysis of the global upper ocean 1950-95. Part I: Methodology. J. Phys. Oceanogr., 30, 294-309, https://doi.org/ 10.1175/1520-0485(2000)030<0294:ASODAA > 2.0.CO;2.

Cessi, P., 2000: Thermal feedback on wind stress as a contributing cause of climate variability. J. Climate, 13, 232-244, https://doi.org/ 10.1175/1520-0442(2000)013<0232:TFOWSA > 2.0.CO;2.

Chu, C., X.-Q. Yang, X. Ren, and T. Zhou, 2013: Response of Northern Hemisphere storm tracks to Indian-western Pacific Ocean warming in atmospheric general circulation models. Climate Dyn., 40, 1057-1070, https://doi.org/10.1007/s00382013-1687-y.

Delworth, T. L., and R. J. Greatbatch, 2000: Multidecadal thermohaline circulation variability driven by atmospheric surface flux forcing. J. Climate, 13, 1481-1495, https://doi.org/10.1175/ 1520-0442(2000)013<1481:MTCVDB > 2.0.CO;2.

Di Lorenzo, E., and Coauthors, 2008: North Pacific Gyre Oscillation links ocean climate and ecosystem change. Geophys. Res. Lett., 35, L08607, https://doi.org/10.1029/2007GL032838. 
Fang, J., and X.-Q. Yang, 2016: Structure and dynamics of decadal anomalies in the wintertime midlatitude North Pacific oceanatmosphere system. Climate Dyn., 47, 1989-2007, https:// doi.org/10.1007/s00382-015-2946-x.

Feliks, Y., M. Ghil, and E. Simonnet, 2004: Low-frequency variability in the midlatitude atmosphere induced by an oceanic thermal front. J. Atmos. Sci., 61, 961-981, https://doi.org/ 10.1175/1520-0469(2004)061<0961:LVITMA > 2.0.CO;2.

,-- , and — 2007: Low-frequency variability in the midlatitude baroclinic atmosphere induced by an oceanic thermal front. J. Atmos. Sci., 64, 97-116, https://doi.org/10.1175/JAS3780.1.

Foltz, G. R., C. Schmid, and R. Lumpkin, 2013: Seasonal cycle of the mixed layer heat budget in the northeastern tropical Atlantic Ocean. J. Climate, 26, 8169-8188, https://doi.org/ 10.1175/JCLI-D-13-00037.1.

Frankignoul, C., P. Müller, and E. Zorita, 1997: A simple model of the decadal response of the ocean to stochastic wind forcing. J. Phys. Oceanogr., 27, 1533-1546, https://doi.org/10.1175/ 1520-0485(1997)027<1533:ASMOTD>2.0.CO;2.

Hasselmann, K., 1976: Stochastic climate models. Part I: Theory. Tellus, 28A, 473-485, https://doi.org/10.3402/tellusa.v28i6.11316.

Horel, J. D., and J. M. Wallace, 1981: Planetary-scale atmospheric phenomena associated with the Southern Oscillation. Mon. Wea. Rev., 109, 813-829, https://doi.org/10.1175/1520-0493(1981)109<0813: PSAPAW $>2.0 . \mathrm{CO} ; 2$.

Hoskins, B. J., and P. J. Valdes, 1990: On the existence of stormtracks. J. Atmos. Sci., 47, 1854-1864, https://doi.org/10.1175/ 1520-0469(1990)047<1854:OTEOST>2.0.CO;2.

Huck, T., and G. K. Vallis, 2001: Linear stability analysis of the threedimensional thermally-driven ocean circulation: Application to interdecadal oscillations. Tellus, 53A, 526-545, https://doi.org/ 10.3402/tellusa.v53i4.12225.

Hurrell, J. W., Y. Kushnir, G. Ottersen, and M. Visbeck, 2003: An overview of the North Atlantic oscillation. The North Atlantic Oscillation: Climatic Significance and Environmental Impact, Geophys. Monogr., Vol. 134, Amer. Geophys. Union, 1-35.

Jin, F.-F., 1997: A theory of interdecadal climate variability of the North Pacific Ocean-atmosphere system. J. Climate, 10, 1821-1835, https:// doi.org/10.1175/1520-0442(1997)010<1821:ATOICV>2.0.CO;2.

Kalnay, E., and Coauthors, 1996: The NCEP/NCAR 40-Year Reanalysis Project. Bull. Amer. Meteor. Soc., 77, 437-472, https://doi.org/ 10.1175/1520-0477(1996)077<0437:TNYRP>2.0.CO;2.

Kwon, Y.-O., M. A. Alexander, N. A. Bond, C. Frankignoul, H. Nakamura, B. Qiu, and L. A. Thompson, 2010: Role of the Gulf Stream and Kuroshio-Oyashio systems in large-scale atmosphere-ocean interaction: A review. J. Climate, 23, 32493281, https://doi.org/10.1175/2010JCLI3343.1.

Latif, M., and T. P. Barnett, 1994: Causes of decadal climate variability over the North Pacific and North America. Science, 266, 634-637, https://doi.org/10.1126/science.266.5185.634.

Li, T., Y. Zhang, E. Lu, and D. Wang, 2002: Relative role of dynamic and thermodynamic processes in the development of the Indian Ocean dipole: An OGCM diagnosis. Geophys. Res. Lett., 29, 2110, https://doi.org/10.1029/2002GL015789.

Lindzen, R. S., and B. Farrell, 1980: A simple approximate result for the maximum growth rate of baroclinic instabilities. J. Atmos. Sci., 37, 1648-1654, https://doi.org/10.1175/15200469(1980)037<1648:ASARFT>2.0.CO;2.

Liu, Z., 2012: Dynamics of interdecadal climate variability: A historical perspective. J. Climate, 25, 1963-1995, https://doi.org/ 10.1175/2011JCLI3980.1.

Mantua, N. J., S. R. Hare, Y. Zhang, J. M. Wallace, and R. C. Francis, 1997: A Pacific interdecadal climate oscillation with impacts on salmon production. Bull. Amer. Meteor. Soc., 78, 1069-1080, https://doi.org/10.1175/1520-0477(1997)078<1069: APICOW $>2.0 . C O ; 2$

Minobe, S., 1997: A 50-70 year climatic oscillation over the North Pacific and North America. Geophys. Res. Lett., 24, 683-686, https://doi.org/10.1029/97GL00504.

— A. Kuwano-Yoshida, N. Komori, S.-P. Xie, and R. J. Small, 2008: Influence of the Gulf Stream on the troposphere. Nature, 452, 206-209, https://doi.org/10.1038/nature06690.

Nakamura, H., and A. S. Kazmin, 2003: Decadal changes in the North Pacific oceanic frontal zones as revealed in ship and satellite observations. J. Geophys. Res., 108, 3078, https:// doi.org/10.1029/1999JC000085.

- , and A. Shimpo, 2004: Seasonal variations in the Southern Hemisphere storm tracks and jet streams as revealed in a reanalysis dataset. J. Climate, 17, 1828-1844, https://doi.org/ 10.1175/1520-0442(2004)017<1828:SVITSH > 2.0.CO;2.

, T. Sampe, Y. Tanimoto, and A. Shimpo, 2004: Observed associations among storm tracks, jet streams and midlatitude oceanic fronts. Earth's Climate: The Ocean-Atmosphere Interaction, Geophys. Monogr., Vol. 147, Amer. Geophys. Union, 329-345.

$\longrightarrow,-$, A. Goto, W. Ohfuchi, and S. P. Xie, 2008: On the importance of midlatitude oceanic frontal zones for the mean state and dominant variability in the tropospheric circulation. Geophys. Res. Lett., 35, L15709, https://doi.org/10.1029/2008GL034010.

Newman, M., and Coauthors, 2016: The Pacific decadal oscillation, revisited. J. Climate, 29, 4399-4427, https://doi.org/10.1175/ JCLI-D-15-0508.1.

Power, S. B., F. Tseitkin, M. Dix, R. Kleeman, R. Colman, and D. Holland, 1995: Stochastic variability at the air-sea interface on decadal timescales. Geophys. Res. Lett., 22, 2593-2596, https://doi.org/10.1029/95GL02655.

Qiu, B., 2003: Kuroshio Extension variability and forcing of the Pacific decadal oscillations: Responses and potential feedback. J. Phys. Oceanogr., 33, 2465-2482, https://doi.org/10.1175/2459.1.

$\longrightarrow$, N. Schneider, and S. Chen, 2007: Coupled decadal variability in the North Pacific: An observationally constrained idealized model. J. Climate, 20, 3602-3620, https://doi.org/10.1175/JCLI4190.1.

Ren, X., X. Yang, and C. Chu, 2010: Seasonal variations of the synoptic-scale transient eddy activity and polar front jet over East Asia. J. Climate, 23, 3222-3233, https://doi.org/10.1175/ 2009JCLI3225.1.

Sampe, T., H. Nakamura, A. Goto, and W. Ohfuchi, 2010: Significance of a midlatitude SST frontal zone in the formation of a storm track and an eddy-driven westerly jet. J. Climate, 23, 1793-1814, https://doi.org/10.1175/2009JCLI3163.1.

Saravanan, R., and J. C. McWilliams, 1998: Advective oceanatmosphere interaction: An analytical stochastic model with implications for decadal variability. J. Climate, 11, 165-188, https:// doi.org/10.1175/1520-0442(1998)011<0165:AOAIAA > 2.0.CO;2.

Schneider, N., and B. D. Cornuelle, 2005: The forcing of the Pacific decadal oscillation. J. Climate, 18, 4355-4373, https://doi.org/ 10.1175/JCLI3527.1.

, A. J. Miller, M. A. Alexander, and C. Deser, 1999: Subduction of decadal North Pacific temperature anomalies: Observations and dynamics. J. Phys. Oceanogr., 29, 1056-1070, https://doi.org/ 10.1175/1520-0485(1999)029<1056:SODNPT>2.0.CO;2.

Stommel, H. M., 1958: The Gulf Stream: A Physical and Dynamical Description. University of California Press, $202 \mathrm{pp}$.

Taguchi, B., H. Nakamura, M. Nonaka, and S.-P. Xie, 2009: Influences of the Kuroshio/Oyashio extensions on air-sea heat exchanges and storm-track activity as revealed in regional atmospheric model 
simulations for the 2003/04 cold season. J. Climate, 22, 6536-6560, https://doi.org/10.1175/2009JCLI2910.1.

Takaya, K., and H. Nakamura, 2001: A formulation of a phaseindependent wave-activity flux for stationary and migratory quasigeostrophic eddies on a zonally varying basic flow. J. Atmos. Sci., 58, 608-627, https://doi.org/10.1175/1520-0469(2001) $058<0608$ :AFOAPI $>2.0 . \mathrm{CO} ; 2$.

Tao, L., X. Sun, and X.-Q. Yang, 2019: The asymmetric atmospheric response to the midlatitude North Pacific SST anomalies. J. Geophys. Res. Atmos., 124, 9222-9240, https://doi.org/ 10.1029/2019JD030500.

Thompson, D. W., and J. M. Wallace, 1998: The Arctic Oscillation signature in the wintertime geopotential height and temperature fields. Geophys. Res. Lett., 25, 1297-1300, https://doi.org/ 10.1029/98GL00950.

$\longrightarrow$, and — 2000: Annular modes in the extratropical circulation. Part I: Month-to-month variability. J. Climate, 13, 1000-1016, https:// doi.org/10.1175/1520-0442(2000)013<1000:AMITEC>2.0.CO;2.

Wallace, J. M., and D. S. Gutzler, 1981: Teleconnections in the geopotential height field during the Northern Hemisphere winter. Mon. Wea. Rev., 109, 784-812, https://doi.org/10.1175/ 1520-0493(1981)109<0784:TITGHF $>2.0$. CO;2.

Wang, L., T. Li, and T. Zhou, 2012: Intraseasonal SST variability and air-sea interaction over the Kuroshio Extension region during boreal summer. J. Climate, 25, 1619-1634, https:// doi.org/10.1175/JCLI-D-11-00109.1.

Wang, L.-Y., X.-Q. Yang, D. Yang, Q. Xie, J. Fang, and X. Sun, 2017: Two typical modes in the variabilities of wintertime North Pacific basin-scale oceanic fronts and associated atmospheric eddy-driven jet. Atmos. Sci. Lett., 18, 373-380, https://doi.org/10.1002/asl.766.

Wang, T., X.-Q. Yang, J. Fang, X. Sun, and X. Ren, 2018: Role of air-sea interaction in the 30-60-day boreal summer intraseasonal oscillation over the western North Pacific. J. Climate, 31, 1653-1680, https://doi.org/10.1175/JCLI-D-17-0109.1.

Yao, Y., Z. Zhong, and X.-Q. Yang, 2016: Numerical experiments of the storm track sensitivity to oceanic frontal strength within the Kuroshio/Oyashio Extensions. J. Geophys. Res. Atmos., 121, 2888-2900, https://doi.org/10.1002/2015JD024381. , and W. Lu, 2017: An observational study of the North Pacific storm-track impact on the midlatitude oceanic front. J. Geophys. Res. Atmos., 122, 6962-6975, https://doi.org/ 10.1002/2016JD026192.

$\longrightarrow, \ldots$, and — 2018: Impacts of the subarctic frontal zone on the North Pacific storm track in the cold season: An observational study. Int. J. Climatol., 38, 2554-2564, https://doi.org/10.1002/joc.5429.

Yu, L., and R. A. Weller, 2007: Objectively analyzed air-sea heat fluxes for the global ice-free oceans (1981-2005). Bull. Amer. Meteor. Soc., 88, 527-540, https://doi.org/10.1175/BAMS-88-4-527.

_ X. Jin, and R. Weller, 2008: Multidecade Global Flux Datasets from the Objectively Analyzed Air-Sea Fluxes (OAFlux) Project: Latent and sensible heat fluxes, ocean evaporation, and related surface meteorological variables. OAFlux Project Tech. Rep. OA-2008-01, 64 pp.

Zhu, Y., and X. Yang, 2003: Joint propagating patterns of SST and SLP anomalies in the North Pacific on bidecadal and pentadecadal timescales. Adv. Atmos. Sci., 20, 694-710, https:// doi.org/10.1007/BF02915396. 